\title{
Detection of free gas and gas hydrate based on 3D seismic data and cone penetration testing: An example from the Nigerian Continental Slope
}

\author{
N. Sultan ${ }^{a,{ }^{\star}}$, M. Voisset ${ }^{a}$, T. Marsset ${ }^{a}$, A.M. Vernant ${ }^{a}$, E. Cauquil ${ }^{b}$, \\ J.L. Colliat ${ }^{b}$ and V. Curinier ${ }^{b}$ \\ a IFREMER, Département Géosciences Marines, BP 70, Plouzané F-29280, France \\ ${ }^{\mathrm{b}} \mathrm{TOTAL}$, France \\ *: Corresponding author : nabil.sultan@ifremer.fr
}

\begin{abstract}
:
We present a new method to characterize free gas, gas hydrates and carbonate concretions occurrence which are considered as high-risk factors for sub-sea developments in the Niger delta. This method is based on the combination of 3D seismic data to the geotechnical site characterizations using piezocone CPTU tests (Cone Penetration Test with additional measurement of the pore water pressure). A special processing of the 3D seismic data has enabled the determination of the interval compressional velocity. Using the effective-medium theory, velocity anomalies (negative and positive) within the first $15 \mathrm{~m}$ were translated in gas hydrate and free gas distribution. The calibration of the $\mathrm{P}$ wave velocity anomalies was done thanks to in-situ geotechnical testing carried out during two oceanographic surveys (2003 and 2004). Comparison between in-situ testing, recovered cores and the prediction of the gas and the gas hydrate distribution based on the compressional wave velocity have shown that 3D seismic data is a valuable tool to identify heterogeneous areas but the use of the piezocone was essential to discriminate between gas hydrate occurrences and carbonate concretions' presence. Furthermore, in-situ compressional wave velocity $\left(V_{p}\right)$ measurements have clearly demonstrated what it was suspected from the 3D seismic data, the co-existence in the study area between gas hydrate and free gas.
\end{abstract}

Keywords: effective-medium theory; free gas; gas hydrate; Niger delta; piezocone 


\section{Introduction}

A large number and variety of surveys have been carried out along the West African margin in recent years, in particular, due to the oil and gas industry. The continental slope off Nigeria is one of the areas where the occurrence near the seafloor of natural gas hydrates has been detected previously by several authors (Hovland and Gallagher 1997, Brooks et al. 2000). This type of gas hydrates accumulation is of special interest to industrial development because they are formed close to the seafloor and possibly could become one of the major risks to any future oil development. Any changes in bottom water temperature and/or in pressure generated by human activity on the seafloor (drilling, laying pipe lines) can destabilize hydrate layers, and potentially result in large landslides and soil failures. On the other hand, gas hydrate may be also at the origin of gas release within the sediment layer that can generate a dramatic modification of the engineering response of the soil. Free gas may increase the sediment compressibility, modify the shear strength of the soil (see Wheeler, 1988, Vanoudheusden et al., 2004 amongst others) and reduce the intrinsic permeability. Thus and for the safe of underwater developments, it is more and more frequently required to detect and quantify the free gas and gas hydrate occurrences within marine sediments.

This work was carried out within the framework of a joint research project (NERIS: Nigeria: Evaluation des RISques) between Ifremer and TOTAL. The main aim of this project is to define a protocol to characterize (detection and quantification) the gas and gas hydrates charged sediment corresponding to high-risk areas (geohazards) by using 3D-seismic data and in-situ geotechnical site investigation. While, the use of the 3D seismic data is fundamental to characterize at a regional scale, the heterogeneity and the extension of the gas and gas-hydrate charged marine sediments, the in-situ geotechnical testing is essential to provide an accurate "truth" for calibration and verification.

In this work, the 3D seismic data available from industry were complemented during two NERIS surveys by different types of other geophysical and geotechnical data collected from the Nigerian continental slope. These data were acquired by using:

1. Different geophysical tools (swath bathymetry and associated imagery, deep towed high-resolution sub-bottom profiles, side-scan sonar images).

2. piston coring used to collect sediment cores and gas hydrates samples;

3. In situ geotechnical measurements using the Ifremer CPTU piezocone (Cone Penetration Test with additional measurement of the pore water pressure). A combination of two special cones (classical CPTU cone and sonic cone) was used.

\section{Geological setting and seafloor features}

The study area is located in the Gulf of Guinea on the West coast of central Africa, south of Nigeria and seaward of the modern Niger Delta (Figure 1). The continental margin off the Niger Delta is undergoing deformation by gravity driven tectonism mainly initiated in response to rapid seaward progradation and to sediment loading of in the successive depocentres. Three regional structural styles are recognized (Damuth, 1994) based on a plethora of studies (Stoneley, 1966; Hospers, 1971; Burke, 1972; Mascle et al., 1973; Delteil et al, 1974, 1976; Emery et al., 1975; Weber and Daukoru, 1975; Lehner and De Ruiter, 1977; Evamy et al., 1978; Whiteman, 1982; Galloway, 1986; Damuth et Link, 1987; Knox and Omatsola, 1989): (1) an upper extensional zone beneath the outer continental shelf characterised by extensive listric growth faults. Growth faulting is induced by load, compaction and differential subsidence resulting from huge sedimentation; (2) an intermediate translational zone beneath the continental slope characterised by shale diapirs 
and ridges dividing the slope into separate intraslope basins. These basins are filled with ponded sediments interbedded by turbidites, mass transport deposits and hemipelagic deposits; (3) a lower compressional zone beneath the lower continental slope and uppermost rise characterised by imbricate thrust structures (toe thrusts). These structural styles indicate that large portions of the thick sedimentary prism are slowly moving downslope by gravity gliding or sliding on decolement level, located within the "mobile shales" series, in a manner analogous to giant mass movements or mega-landslides.

Various studies from the Nigerian continental slope have shown different seafloor sedimentary features such as pockmarks, gas hydrates, slides, mud volcanoes and carbonate build-ups associated with fluid flow (Damuth, 1994; Cohen and McClay, 1996; Brooks et al, 2000; Haskell et al., 1999; Hovland et al., 1997; Nissen et al., 1999; Graue, 2000; Deptuck et al. 2003 amongst others). Heggland (2003) observed gas chimneys above hydrocarbon charged reservoirs. These chimneys are believed to result from hydrocarbon dysmigration along fault planes between source rocks of reservoirs and the seabed.

The study area (Figure 1), from a tectonostratigraphic point of view, is within the translational zone (ridges and intraslope basins filled by turbidites among other deposits). The investigated area lies at water depths ranging from $\sim 1100$ to $1250 \mathrm{~m}$ and is characterised by numerous circular to sub-circular features, few $\mathrm{m}$ up to $700 \mathrm{~m}$ in diameter, and by numerous oblong patches (Le Chevalier, 2002). Most of these features are located within a NW-SE trend area bounded by two lineaments clearly expressed on the bathymetry map (Figure 1). The two lineaments (N1 and N3 - Figure 2) correspond to deep-rooted normal faults, which delineate a graben collapsed zone linked to the axis of a subsurface anticline structure (Figure 2).

The seafloor features display various shapes (Figure1 ): 1) a large scale circular depression about $110 \mathrm{~m}$ deep and $700 \mathrm{~m}$ in diameter interpreted as a giant pockmark; 2) typical small scale circular depressions, referred to as pockmarks (Hovland and Judd, 1988), which reveal different stages of development within disturbed sediments; 3) more atypical irregular structures on the seafloor, with a great variability in morphology, size $(100-400 \mathrm{~m}$ in diameter) and acoustic characteristics. The distribution of pockmarks seems related to the distribution of gas/fluid migration paths caused by pre-existing vertical weakness zones (i.e. fault planes) within the shallow sediments. Numerous small scale pockmarks line up along underlying southern major fault plane, thus suggesting the presence of migration pathway along this fault up to the sea-floor (Figure 1). 


\section{Methods and tools}

\section{DeltaStack 3D: Interval velocity from 3D seismic data}

Because the heterogeneity of gas-hydrate charged marine sediment, the use of the seismic data to determine the gas hydrate distribution is of great interest for the evaluation of the risk associated to gas hydrate dynamics. Thanks to the high quality 3D seismic data available in the studied area, it was decided to process these data in order to provide 3D attributes, in particular interval velocity, using DeltaStack 3D (Arnaud et al. 2004, Cauquil et al. 2005). DeltaStack 3D is an automatic 3D high-density velocity picking tool developed by TOTAL. It consists in the determination of a residual normal-move out correction in the Radon domain. It provides 3D high-density velocity analyses at each Common Mid Point gather. The time density of picking depends on the frequency content of the input seismic data. The output of such a process is a geophysical velocity field, called stacking velocity, from which an interval velocity field (or P wave velocity) can be computed. The later can be linked to petrophysical properties of the formations.

This process allows a fully automatic velocity picking and the human input is limited to the definition of constraints along a set of so-called "seed lines". These constraints, which drive the picking, are then propagated and are self-adaptive to the geological variations of the subsurface.

In this case, because the processing of the seismic data is adapted to the shallow target the quality of the data is optimal in the first 500 ms-twt window below the sea bottom. Thanks to the good quality of data, the results obtained from DeltaStack3D processing are stable and with a good signal-to-noise ratio. The seismic bandwidth at the sea bottom is about $70 \mathrm{~Hz}$, which leads to a minimum time between 2 consecutive velocity analyses of 14 msec. If we consider an average velocity of $1600 \mathrm{~m} / \mathrm{sec}$ the resulting resolution is about $11 \mathrm{~m}$. There is a satisfying alignment of detection (i.e. the times when velocity analysis is made) with the seismic markers, which leads to a spatially coherent velocity field.

\section{Geotechnical data: in-situ measurements and laboratory tests}

\section{In-situ measurements}

In-situ geotechnical measurements were carried out using the Ifremer piezocone CPTU during the NERIS2 oceanographic survey (2004). This seabed piezocone is able to perform in-situ geotechnical measurements in deep sea (up to $6000 \mathrm{~m}$ of water depth) with a maximum depth of investigation of 30 metres below the sea bottom. A combination of two special cones (classical CPTU cone and sonic cone) was used in the investigation (see Figure 3).

The CPTU cone includes 3 modules: 1 ) a lower module including the geotechnical sensors: point resistance, lateral friction, differential pore pressure on a porous ring situated above the cone, 2) a module including a source of Cesium 137 of weak energy for the measurement of the unit weight and 3) a third module including two inclinometers placed in two perpendicular planes and a thermometer. More details concerning the Ifremer $C P T U$ piezocone are presented in Meunier et al. (2004).

In the Cone Penetration Test a cone (Figure 3-a) on the end of coiled tubing is pushed into the soil layers at a constant rate. The electric cone used during the NERIS2 cruise gave a continuous measurement of the tip resistance $(q c)$, sleeve friction $(f s)$ and excess pore pressure $\left(\Delta u_{2}\right)$ measured by means of a porous filter located immediately behind the cone (called U2 type cone). The maximum penetration of the CPTU is $30 \mathrm{~m}$ below the seafloor (mbsf). From the $C P T U$ parameters $q c$ and $\Delta u_{2}$, the corrected cone resistance qt can be derived according to the following equations: 


$$
q t=q c+(1-\alpha)\left(\Delta u_{2}+u_{h}\right)
$$

where $\alpha$ is the effective cone section ratio and $u_{h}$ is the hydrostatic pore pressure.

The net cone resistance $q_{\text {net }}$ is given by the following equation:

$$
q_{n e t}=q t-\sigma_{v}
$$

where $\sigma_{v}$ is the vertical total stress at the cone base.

The geometry of the cone penetrometer with tip, sleeve and pore pressure filters used within the NERIS2 cruise follows the International Reference Test Procedure for Cone Penetration Test (CPT) (ISSMGE 1999).

The sonic CPT is a technology improvement to the standard cone penetrometer. The end of the coiled tubing holds two tips (Figure 3-b) where the first one contains a high-frequency compression wave source $(1 \mathrm{MHz})$ and the second tip the receiver. The distance between receiver and source is equal to $0.07 \mathrm{~m}$ (Figure 3-b). In order to increase the accuracy of the measurement, the compression wave is made over 1000 measurements. As for the classical penetrometer, the sonic $C P T$ is pushed into the sediment layers at a constant rate. A continuous measurement of the $\mathrm{P}$ wave velocity and the attenuation is made. In the study area, we carried out a total of 21 CPTU and sonic measurements (Table 1).

\section{Laboratory testing}

\section{Saturated sediment}

Besides the in-situ measurements carried out during the NERIS2 survey, an experimental program on undisturbed marine sediments from core N2-KSF43 (Table 1) has been undertaken. The aim is to identify the key parameters needed to express the $\mathrm{P}$ wave velocity anomalies in terms of gas and gas hydrates concentration. The detailed laboratory geotechnical investigation includes:

1- Classification tests;

2- Consolidation/permeability tests;

3- Strength tests.

Classification testing of samples is carried out to identify soil type it includes grain size analysis, moisture content determinations, direct $\mathrm{P}$ wave measurements.

Shear strengths determined from laboratory tests were performed using the shear vane on undisturbed samples obtained from core N2-KSF-43.

Consolidation test is performed to give the compressibility characteristics of the soil and important input related to the stress history of the soil. The consolidation tests were carried out using the oedometer with incremental loading. In addition, the permeability coefficient was determined at each loading steps.

\section{Sediment partially saturated by gas}

A special triaxial cell (Figure 4) was developed in order to identify the acoustic properties of the sediment recovered from the study area and partially saturated by gas. In the cell the axis translation method, which permits the independent control of gas and water pressures, allowing full control of the gas-water pressure difference (i.e. capillary pressure) was used. The two different pressures on both fluids (carbon dioxide and water) are imposed by means of a ceramic porous stone. The main characteristic of this porous stone is its very small pore diameter, and consequently the high capillary pressure, that can be imposed between the two fluids. The disadvantage of this method is the test duration, which can be very long due to the low permeability of the porous stone. In addition, measurements of the compression wave 
$\left(V_{p}\right)$ and shear wave $\left(V_{s}\right)$ velocities during the test were achieved using GDS bender elements (Brignoli et al. 1996). 


\section{Results}

\section{Interval velocity from $3 D$ seismic data}

We applied the DeltaStack3D processing to derive the interval velocity over the upper 10 reflectors. Figure 5 illustrates the projection on the seafloor of the velocity deviation from the reflector mean value for the first upper 4 reflectors. The first reflector represents the upper $15 \mathrm{~m}$ below the seafloor (mbsf) (Figure5 -a), the second, third and fourth reflectors characterize respectively the sediment at around 40 mbsf, 60 mbsf and 80 mbsf (Figure 5 -b, c and $-d$ ). The seismic amplitude on the water bottom shows an anomalous area indicated in Figure 5-a, which might be due to the acquisition or processing sequence. Figure5 shows that the velocity deviation increases at the second and the third reflectors which is probably an indication of higher activity at the corresponding depth. In this work, only the $\mathrm{P}$ wave velocities from the first reflector are studied as it can be calibrated by CPTU measurements and piston coring. A detailed study of the $\mathrm{P}$ wave velocity obtained from the first reflector, before the second NERIS cruise, has allowed the identification of several heterogeneous areas and the focus of the geotechnical site investigation during the NERIS2 survey on those probable high-risk areas.

\section{Geotechnical data from in-situ testing}

\section{CPTUs testing}

During the NERIS1 cruise, several recovered gravity cores have shown the existence of gas hydrate in some areas and the existence of carbonate concretions in others. By comparing the cores indications in terms of gas hydrate and carbonate concretions it was clear that the 3D seismic data gave an important signal (high $\mathrm{P}$ wave velocity) on both the existence of gas hydrate and carbonate concretions. Thus, several sites were chosen for in-situ measurements in order to calibrate the map of velocity anomalies obtained from the 3D seismic data. Three CPTUs were done in the gas hydrate areas (PM27-A, PM33-B and PM33-C) and six CPTUs were carried out in the carbonate concretion areas (PM22-A, PM22-B, PM22-C, PM23-A, PM23-B and PM23-Bbis) (for position see Figure 6). All CPTUs performed in the suspected zones with concretions and/or gas hydrates are characterized by early refusal at depth between $5 \mathrm{~m}$ and $18 \mathrm{~m}$ with high cone resistance values (qt ranging between 10 and $25 \mathrm{MPa}$ ). In the following the results of the CPTUs measurements from 4 typical sites will be presented.

Figure 7 shows the vertical effective stress $\sigma_{v}$ derived from the unit weight measurements, the corrected cone resistance $q t$, the friction $f s$ and the pore pressure $u_{2}$ as a function of depth. The PM33-D in-situ testing site presented in Figure 7 was considered from the 3D seismic data as a reference site (for position see Figure 6). Sediment from PM33-D is characterized by a very low unit weight measured in-situ thanks to the source of Cesium 137 (around $12.5 \mathrm{kN} / \mathrm{m}^{3}$ ). The corrected cone resistance, the friction and the excess pore pressure increase linearly with depth confirming the reference site guess identified from the 3D seismic data. At 30 mbsf, the corrected cone resistance qt is around $650 \mathrm{kPa}$, the friction $\mathrm{fs}$ is around $22 \mathrm{kPa}$ and the excess pore pressure $\Delta u_{2}$ is around $236 \mathrm{kPa}$. On the other hand, we can see clearly apparent over-consolidated sediment over the first meter at the site PM33-D. This apparent over-consolidation over the upper sediment was observed in several areas from West Africa and is probably related to the pore water activity (Sultan et al, 2001).

Figure 8 shows the vertical effective stress, the corrected cone resistance, the friction and the pore pressure $u_{2}$ as a function of depth for an area were the existence of free gas was suspected because of the low $\mathrm{P}$ wave velocities (for position Figure 6). Once again, PM33-E is characterized by a low unit weight (Figure 8-a), at $30 \mathrm{mbsf}$ the corrected cone resistance is 
around $670 \mathrm{kPa}$, the friction is around $24 \mathrm{kPa}$ and the excess pore pressure is around $413 \mathrm{kPa}$. Comparison between Figure7 and Figure 8 indicate that the excess pore pressure $\Delta u_{2}$ generated by the rod penetration at the site PM33-E is twice the $\Delta u_{2}$ generated at the site PM33-D. The free gas is probably at the origin of the high excess pore pressure at the site PM33-E. The temperature increases generated by the rod penetration could cause a volume expansion of the free gas (and probably gas exsolution) leading to an increase of the excess pore pressure. In addition, a result of the gas occurrence is a decrease of the soil permeability and consequently an increase of the excess pore pressure generated during the rod penetration. This feature of high excess pore pressure at gassy sites was confirmed at the other sites where the gas occurrence was suspected. Once again, we can observe the apparent overconsolidation over the first meter of the sediment from PM33-E site.

Figure 9 shows the vertical effective stress $\sigma_{v}$, the corrected cone resistance $q t$, the friction $f s$ and the pore pressure $u_{2}$ as a function of depth for an area were the existence of gas hydrates was identified thanks to the gravity core KSF-20 collected during the NERIS1 cruise (Figure 10-a). Besides, the gas hydrate existence was suspected from the high $\mathrm{P}$ wave velocity values derived from the 3D seismic data (for position Figure 6). From Figure 9-a it is possible to see the clear decrease of the vertical effective stress at around 2.4 mbsf. At the same depth, Figure 9-b,c\&d shows a sudden increase of the corrected cone resistance of the friction and of the excess pore pressure. The measurement results presented in Figure 9 confirm the existence of the gas hydrate which is characterized by a low unit weight and induce the decrease of the vertical effective stress $\left(\sigma_{v}^{\prime}\right)$, high strength resistance (increase of $q t$ and $f s$ ) and low permeability (increase of $\Delta u_{2}$ ). Curiously, the apparent over-consolidation observed from the former two sites (PM33-D and PM33-E) has disappeared at the site PM27-A.

Figure 11 shows the vertical effective stress $\sigma_{v}^{\prime}$, the corrected cone resistance $q t$, the friction $f s$ and the pore pressure $u_{2}$ as a function of depth for an area (site PM23-A) were the existence of carbonate concretions was identified thanks to gravity cores collected during the NERIS1 cruise (Figure 10-b). Besides, at this site, high $\mathrm{P}$ wave velocity values derived from the 3D seismic data show positive anomalies. At around $4 \mathrm{mbsf}$, Figure 11-b\&c shows a sudden increase of the corrected cone resistance and the friction. The excess pore pressure generated by the rod penetration was, for several levels at the site PM33-A, lower than the hydrostatic pressure (Figure 11-d). The high permeability of the carbonate concretions and the dilatancy generated by the friction are probably at the origin of the negative pore pressure presented in Figure 11-d.

The measurement results presented in Figure 11 confirm the existence of the carbonate concretions, which is characterized by a high strength resistance (increase of $q t$ and $f s$ ), high permeability (decrease of $\Delta u_{2}$ ) and a normal density characterized by a linear increase with depth of the vertical effective stress.

\section{Sonic CPTs testing}

In the study area, 4 Sonic Cone Penetration Tests (Sonic CPT) were carried out in three different environments (for location see Figure 6):

- Two Sonic CPTs (PV39-A and PV40-A) were done in two areas where we have evidence (from the NERIS1 cruise) of gas-hydrate charged marine sediment (Figure 6).

- One Sonic CPT (PV39-B) was done in an area where we have evidence (from the NERIS1 cruise) of carbonate concretions (Figure 6).

- One Sonic CPT (PV40-B) was done in a supposed reference area far from the different disturbed zones (pockmarks, gas hydrate, gas and carbonate) observed in area B. 
The maximum range of measurement of the $\mathrm{P}$ wave sensor is $2000 \mathrm{~m} / \mathrm{s}$. That is why, for the two sites PV39-A and PV40-A the P wave measurements were blocked-up (exceeding the $2000 \mathrm{~m} / \mathrm{s}$ in hydrate) at several depths.

For the site PV39-A, the gas hydrate was probably touched at around 8 mbsf (Figure 12-a). It is interesting to see that at site PM27-A, which is at a distance of $20 \mathrm{~m}$ from site PV39-A, the gas hydrate was met at around 3 mbsf (Figure 9). From those two sites (PM27-A and PV39A) we can notice the heterogeneous distribution of the gas hydrate within the sediment of the study area.

In Figure 12 are presented values of the $\mathrm{P}$ wave velocity obtained from the 3D seismic data over the first reflector corresponding approximately to the upper $15 \mathrm{~m}$ of sediment. From Figure 12 a difference can be observed between measured $\mathrm{P}$ wave velocities (from in-situ) and calculated ones from the 3D seismic data. On the other hand, we can remark the increase of the mean $\mathrm{P}$ wave velocities obtained from the 3D seismic data and the in-situ measurements with hydrate occurrence (Figure 12).

At the site PV39-B (Figure 12-b), we can observe an abrupt increase of the $\mathrm{P}$ wave velocity $(\approx 20 \mathrm{~m} / \mathrm{s})$ at around $14 \mathrm{mbsf}$. This increase is probably related to the presence of carbonate concretions. At an adjacent site (PM23-A), the carbonate concretions were met at around 4.5 mbsf (Figure 11).

For the site PV40-A, the gas hydrate was touched at around 1 mbsf (Figure 12-c) while it was met at around 6 mbsf at the adjacent site PM33-B. Once again, Figure 12-c apparently shows evidence of the co-existence of the gas and the gas hydrate.

The reference site (PV40-B) shows uniform values of the $\mathrm{P}$ wave velocities over the first $12 \mathrm{~m}$ corresponding to the first reflector from the 3D seismic data (Figure 12-d). The mean value of $V_{p}$ is around $1465 \mathrm{~m} / \mathrm{s}$, which fits well with the upper values of $V_{p}$ above the carbonate concretions at the site PV39-B (Figure 12-b).

\section{Geotechnical data from laboratory measurements}

\section{Saturated sediment}

The results of the classification tests are presented in Figure 13 (a, b, e, f). Results from Figure 13 show the existence of two layers with a clear boundary at around 5 mbsf. The upper layer is more silty than the lower one (Figure 13-f). It is important to mention that ultrasounds were applied during 2 minutes to an untreated samples (dispersing agents) before the grain size distribution tests which may have underestimated the clay content (see for instance Thomas et al., 2005). The high clay content of the lower sediment layer induces a decrease of the $\mathrm{P}$ wave velocity from $1490 \mathrm{~m} / \mathrm{s}$ at the upper layer to around $1480 \mathrm{~m} / \mathrm{s}$ for the lower one (Figure 13-e).

Disparity between the mean $\mathrm{P}$ wave velocities obtained from in-situ testing using the Sonic $C P T$ (around $1480 \mathrm{~m} / \mathrm{s}$ from Figure 12) and the one obtained from laboratory (around $1465 \mathrm{~m} / \mathrm{s}$ from Figure 13-e) is partly related to the temperature changes between in-situ $\left(\approx 4^{\circ} \mathrm{C}\right)$ and laboratory $\left(20^{\circ} \mathrm{C}\right)$. The used of two different sensors even with the same characteristics and frequency have also contributed to this difference.

Results of the shear vane tests are presented in Figure 13-c. Figure 13-d shows the rate between the undrained shear strength $S u$ and the effective stress $\sigma^{\prime}{ }_{v}$ which depends on the stress history of the sediment and the lithology (Skempton, 1954). Once again a clear limit can be observed between the upper layer where $\frac{S u}{\sigma_{v}}$ is equal to 0.8 and the lower layer where $\frac{S u}{\sigma_{v}}$ is equal to 0.35 . 
Results of the consolidation tests in terms of compressibility and permeability coefficients are presented in Figure14 (a \& b). Due to the silt content, for the same void ratio, the permeability of the sample S3 (at around $3 \mathrm{mbsf}$ ) is higher than the permeability of the other two samples S8 and S10. However, the compressibility of the three samples seems not affected by the silt content (Figure 14-a).

\section{Sediment partially saturated by gas}

In order to characterize experimentally the acoustic properties of the sediment, triaxial test using the special triaxial cell (Figure4) was carried out on undisturbed sample recovered at around 12 mbsf from core N2-KSF43. Figure 15-a shows the four stress paths in a confining pressure - capillary pressure diagram. The sample was firstly saturated under a capillary pressure $p_{c}$ ( $p_{c}=$ gas pressure - pore water pressure) of $25 \mathrm{kPa}$ and an effective confining pressure of $50 \mathrm{kPa}$ (back pressure of $600 \mathrm{kPa}$ ). After equilibrium, the effective confining pressure was increased by increment from $50 \mathrm{kPa}$ to $800 \mathrm{kPa}$ (stress C1 - Figure 15-a). At each loading step, the $\mathrm{P}$ wave and the $\mathrm{S}$ wave velocities was measured. The second stress path (stress C2 - Figure 15-a) corresponds to an increase by steps of the capillary pressure (or increase of the gas degree of saturation).

Figure 15-b-c shows the effect of the consolidation state (void ratio) and the degree of saturation on the compressional wave and shear wave velocities. Figure 15-b shows the experimental results in terms of void ratio versus $\mathrm{P}$ wave velocities for the stress path $\mathrm{C} 1$ and $\mathrm{C} 2$. For $\mathrm{C} 1$, the increase of the effective confining pressure has induced a decrease of the void ratio under the same capillary pressure $\left(p_{c}=25 \mathrm{kPa}\right)$. The consequence of the void ratio decrease under a constant capillary pressure is an increase of the $\mathrm{P}$ wave velocity (Figure 15b: path C1). For path C2, under a constant effective confining pressure, the capillary pressure was increased from $25 \mathrm{kPa}$ to $500 \mathrm{kPa}$. Although, the increase of the gas degree of saturation was associated to a densification of the sediment, the effect of the capillary pressure increase was predominant on the $\mathrm{P}$ wave velocity (Figure 15-b). The $\mathrm{P}$ wave velocity under the path C2 drops down to around $1017 \mathrm{~m} / \mathrm{s}$. Figure 15-c shows the experimental results in terms of void ratio versus shear-wave velocities for the stress path $\mathrm{C} 1$ and $\mathrm{C} 2$. The effect of the capillary pressure seems negligible with respect to the densification effect. Under the stress paths $\mathrm{C} 1$ and $\mathrm{C} 2$, Figure 15-c shows a quasi-unique curve between the void ratio and the shear wave velocities independently from the capillary pressure (or the gas degree of saturation). 


\section{Discussion}

\section{Relationship between capillary pressure and gas saturation}

The aim of the laboratory characterisation of the acoustic properties of the sediment partially saturated by gas is to identify the gas degree of saturation from the $\mathrm{P}$ wave velocities derived from the 3D seismic data (Figure5). From the experimental tests presented in Figure 15-a\&b it is possible to distinguish a link between the $\mathrm{P}$ wave velocities and the capillary pressure. In sediment partially saturated by gas, a fundamental correlation between the water (wetting phase) and the gas (non-wetting phase) saturation and the capillary pressure exists. An increase of the gas saturation leads to an increase of the capillary pressure and consequently, a retreat of the water to smaller pores. A large number of scientists have already tried to derive empirical correlation between capillary pressure and saturation. The most famous models are models of air-water system developed by Leverett (1941) and Van Genuchten (1980). These simple models implicitly assumed to account for all effects and processes that influence the equilibrium distribution of fluids. In this work the Van Genuchten (1980) equation which proposed a relationship, between the degree of saturation $S_{w}$ and the capillary pressure $p_{c}$, for the whole range of degree of saturation is used (eq 1):

$$
p_{C}=u_{g}-u_{w}=\frac{\left[\left(\frac{s_{w}-\theta_{r}}{\theta_{S}-\theta_{r}}\right)^{\frac{-1}{m}}-1\right]^{\frac{1}{n}}}{\alpha}
$$

where $u_{g}$ is the gas pressure, $u_{w}$ is the pore water pressure, $p_{c}$ is the capillary pressure, $S_{w}$ is the water degree of saturation and $\theta_{r}, \theta_{s}, \alpha, m$ and $n$ are five shape parameters presented in Figure 16-a.

In this work, relationship between the capillary pressure and the degree of water saturation (porosimeter curves) obtained by De Gennaro et al. (2004) on equivalent sediment from West Africa were used. De Gennaro et al. (2004) have used the Mercury Intrusion Porosimetry (MIP) on two freeze dried samples (with two initial void ratio of 3.1 and 2).

By fitting equation 1 to experimental results of De Gennaro et al. (2004), two sets of parameters were identified for two initial void ratios (Table 2). The parameter $\alpha$ is the only one changing between the two sets of parameters (table 2). For the five other void ratio $e$ of the C2 path of Figure 15-b, the parameter $\alpha$ was extrapolated from the two values of $\alpha$ (for $\mathrm{e}=3.1$ and $\mathrm{e}=2$ ). The total set of parameters for 7 different initial void ratios is presented in Table 2. Figure16 shows the evolution of the retention curve for these void ratios. Thanks to the curves of Figure16, it was possible to identify the water degree of saturation corresponding to the capillary pressure of the experimental tests of path C2. Figure 16-b shows the experimental results of the stress path $\mathrm{C} 2$ in a diagram (a) water degree of saturation-compressional wave velocity and (b) water degree of saturation-shear wave velocity. While the water degree of saturation from Figure 16-b varies between $100 \%$ and $91.7 \%$ the $\mathrm{P}$ wave velocity is between $1503 \mathrm{~m} / \mathrm{s}$ and $1017 \mathrm{~m} / \mathrm{s}$ and the shear wave velocity is between $138 \mathrm{~m} / \mathrm{s}$ and $221 \mathrm{~m} / \mathrm{s}$.

\section{Velocity anomalies from 3D seismic data and free gas and gas hydrate saturation}

In marine field conditions where gas hydrate occurrences are suspected, positive velocity anomalies (velocities higher than those of water-filled normally compacted sediment) are 
attributed to existence of gas hydrate while lower velocities are attributed to existence of free gas. Hydrate's high $\mathrm{P}$ wave velocity can increase the $\mathrm{P}$ wave velocity in hydrate bearing sediments. In the study area, the presence of carbonate concretions makes things more complex. We have confirmed that carbonate concretions are also characterized by high $\mathrm{P}$ wave velocities. As a first approach, our work hypothesis was to consider that the high $\mathrm{P}$ wave velocities correspond only to the presence of gas hydrates.

Several methods were developed in order to translate those velocity anomalies to gas and gas hydrate concentrations. Chand et al. (2004) tested four models to convert velocity anomalies to gas hydrate saturation. Those models are 1) the empirical weighted equation (WE - Lee et al. 1996); 2) the three-phase effective-medium theory (TPEM - Ecker et al. 1998, Helgerud et al. 1999 and Ecker et al. 2000); 3) the three-phase Biot theory (TPB - Carcione and Tinivella 2000 and Gei and Carcione 2003) and 4) the differential effective-medium theory (DEM Jackobsen et al. 2000). These models are based on the effective medium theory; the combination of the elastic properties of each constituent (solid grains, water, hydrate and gas) gives the acoustic properties of the composite sediment. Chand et al. (2004) compared these different models for a range of variables (porosity and clay content) using standard values for physical parameters. The conclusion of Chand et al. (2004) shows that all the models predict sediment properties comparable to field values except for the WE model at lower porosities and the TPB model at higher porosities. In this work, we have used the TPEM method as it is described by Helgerud et al (1999).

The Helgerud et al. model (1999) considers the gas hydrate as either a component of the matrix or filling the pores. The gas hydrate recovered from the gravity cores was often massive (see Figure 10-a) and rarely disseminates in the sediment pores. Figure 17-a and Figure 17-b show the top of the GHOZ at site PM27-A which is around 3 mbsf. The presence of gas hydrate at this site is characterized by a decrease of the mass density of the hydratebearing sediments and an important increase of the cone resistance qt. From the mass-density and the cone resistance $q t$, it was possible to calculate the hydrate fraction $\eta$ and the internal friction angle $\varphi\left(^{\circ}\right)$.Figure 17-c shows clearly the effect of the hydrate fraction on the increase of the internal friction angle and illustrates that the important increase of the internal friction angle occurred at low hydrate fraction $(<2 \%)$. Results from Figure17 confirm that in the study area, the gas hydrate acts as a cementing agent between grains and can be considered as a part of the sediment matrix (Sultan, 2007). Massive nodules of gas hydrate detected thanks to coring can be considered as a component of the sediment matrix with a hypothetical porosity of 1 . Therefore, in the following, the gas hydrate is considered as a component of the matrix, which must be considered as a lower bound of the prediction of the gas hydrate concentration.

Based on laboratory geotechnical tests carried out core N2-KSF43, it was possible to identify the key parameters used in the Helgerud et al. model (1999). The compressibility of the sediment giving the change of the porosity as a function of depth was derived from the oedometer tests (see Figure14). The classification tests presented in Figure13 were necessary to characterize the lithology of the upper $15 \mathrm{~m}$ of the sediment corresponding to the interval velocity over the first reflector. Using Helgerud et al.'s (1999) effective-medium theory, we calculate gas saturations corresponding to the $\mathrm{P}$ wave velocities obtained from the experimental tests (Figure15 and Figure16). In the Helgerud model, we assume that the average number of grain contacts is 9. Physical and mechanical parameters used in the Helgerud et al. (1999) approach are presented in Table 3. The prediction of the $\mathrm{P}$ wave velocities and shear wave velocities using the Helgerud's et al. model are added to Figure 16a. A good agreement can be observed between the prediction and the experimental results concerning the effect of the gas content on the compressional and shear wave velocities. 
Based on the mechanical and physical properties identified thanks to laboratory tests, the P wave velocity anomalies obtained from the 3D seismic data (Figure5) was used to determine the distribution and saturations of gas hydrate and free gas using the Helgerud et al. model (Figure18). Gas and hydrate saturation of pore space varies significantly along the study area. Highest hydrate saturations correspond to $30 \%$ of pore space averaged over the first $15 \mathrm{~m}$ while highest gas saturations correspond to $1 \%$ of the pore space. It is important to mention that the gas and gas hydrate fraction corresponds to the mean value over the first reflector which represents the first $15 \mathrm{~m}$ below the seafloor.

\section{Comparison between free-gas and gas hydrate prediction and in-situ measurements}

Figure19 shows the distribution and saturations of gas hydrate and free gas for the western part of the study area. Two main targets (A1 and B1) were selected in order to compare the gas and gas hydrate prediction from the 3D seismic data to the in-situ testing. The target A1 concerns a pockmark where the northern and the western part are characterized, according to the 3D seismic data, by gas hydrate occurrence. On the other hand and according to the 3D seismic data free gas occurs at the eastern and southern part of the pockmark.

Piezocone results from site PM33-E were presented in Figure8 and it seems probable at this site the existence of free gas. A low $\mathrm{P}$ wave velocity over the first reflector (equivalent to the upper $15 \mathrm{~m}$ of sediment) characterizes the PM33-F site. Piezocone results for the site PM33-F is comparable to the site PM33-E, the excess pore pressure generated by the rod penetration is high which is probably related to the presence of free gas. Piezocone results for the site PM33-G in terms of corrected cone resistance and excess pore pressure are comparable to the reference site presented in Figure7. Sites PM16-A and PM16-B are positioned in a neutral area without any $\mathrm{P}$ wave velocity anomalies. Results from CPTUs PM16-A and PM16-B in terms of corrected cone resistance and excess pore pressure confirmed the reference sites over the upper $15 \mathrm{~m}$ of sediment as it was observed from the first reflector of the 3D seismic data.

The second target (B1 in Figure19) concerns a peanut-shape pockmark. In this pockmark, 5 CPTUs (PM22-B, PM22-C, PM23-A, PM23-B and PM23-Bbis) and 1 Sonic CPT (PV39-B) were carried out. Cores recovered during the NERIS1 cruise from the pockmark have shown the existence of carbonate concretions. On the other hand, and based on the 3D seismic data, gas hydrates occurrence was predicted at the same pockmark. CPTU results from site PM23A (Figure11) have demonstrated the existence of carbonate concretions and not gas hydrates. All the CPTUs measurements (PM22-B, PM22-C, PM23-B and PM23-Bbis) carried out in the peanut-shape pockmark show a high "corrected cone resistance" with a low "excess pore pressure" which confirm the existence of carbonate concretions in the peanut-shape pockmark. A high $\mathrm{P}$ wave velocity comparable to the one of the gas hydrate characterizes the carbonate hardground. For this reason, the $\mathrm{P}$ wave velocity values alone it not enough to distinguish between gas hydrates occurrence and the presence of carbonate concretions.

Figure19 shows the distribution and saturations of gas hydrate and free gas for the eastern part of the study area. Four main objects (A2, B2, C2 and D2) were selected in order to compare the gas and gas hydrate prediction from the 3D seismic data to the in-situ testing. Cores recovered from the three areas A2, B2 and C2 during the Neris1 survey (KSF20, KSF23, KS36 and KSF37 - see Figure6 for position) have shown the existence of massive gas hydrates at depths between 4 mbsf and 8 mbsf (Figure 10-a). On the other hand, three cores recovered from the area D2 (KS22, KSF28 and KSF32 - see Figure6 for position) have shown the existence of carbonate concretions. The gas hydrate distribution obtained from the 3D seismic data confirms the existence of the gas hydrate for the three areas A2, B2 and C2 (Figure19). As for the western study area, the presence of the carbonate concretions from the area D2 was predicted from the 3D seismic data as gas hydrate occurrences. The three CPTUs 
and two Sonic CPTs carried out in the area B2 and C2 of the eastern part of the study area confirm the existence of the gas hydrate.

Several studies from different margins have shown that carbonate concretions may be a product of methane from decomposing gas hydrate (Suess et al., 1985; Westbrook et al., 1993; Bohrmann et al., 1998; Torres et al., 1999 and Hovland et al., 2005 amongst other). The co-existence between gas hydrate and carbonate concretion as the one recovered from cores KS22, KSF28, and KSF32 (Figure18) was not observed in the study area. However, given the small section of the $C P T U$ rod $\left(10 \mathrm{~cm}^{2}\right)$ and the high resistance of the carbonate concretions and gas hydrates which when met impede further penetration of the CPTU cone this coexistence remains possible.

\section{Co-existence of free gas and gas hydrate}

In addition to the in-situ testing and the 3D seismic data, the investigation of the studied area was carried out by using different geophysical tools (swath bathymetry and associated imagery, deep towed high-resolution sub-bottom profiles, side-scan sonar images). A detailed work concerning the presentation and the interpretation of those geophysical data is done by Marsset et al. (2005). Figure19 shows the sub-bottom profile N1CH08 acquired across the PV39-A site (for location see Figure1). The low $P$ wave velocities (down to $870 \mathrm{~m} / \mathrm{s}$ ) recorded from the site PV39-A is certainly linked to the presence of free gas. This could mean the co-existence of the gas and the gas hydrate at this site. Furthermore, N1CH08 profile reveals the presence of an acoustic mask, which is consistent with the PV39-A site where insitu $V_{p}$ measurements have shown a co-existence between gas and gas hydrates. In this area it is possible that free gas migrates upwards from beneath the hydrate stability zone. Those results are consistent with Marsset et al. (2005) observations; they have shown that in this area, the co-existence of the gas and the gas hydrate is recurrent.

The co-existence between free gas and gas hydrate has recently been reported from the Oregon continental margin where according to different authors high salinity has changed locally the thermodynamic conditions of the gas hydrate stability allowing the movement of free gas through the Gas Hydrate Stability Zone (Tréhu et al., 2003; Milkov et al., 2004; Torres et al., 2004; and Liu et al., 2006). Due to the relative high water depth and the low temperature in the present study area, the process at the origin of the co-existence of free gas and gas hydrates is probably not similar to the Oregon margin. For pure methane at $1190 \mathrm{~m}$ of water depth and seafloor temperature of $4.1{ }^{\circ} \mathrm{C}$, a salinity of around $200 \mathrm{~g} / \mathrm{L}$ is needed to avoid the formation of methane hydrate. A tentative explanation of the co-existence between gas and gas hydrate in the study area is the high free gas migration within the pore of the gas hydrate where the absence of water prevents the formation of gas hydrate (Tréhu et al., 2004).

\section{Conclusion}

The main aim of this work was the definition of a protocol to characterize free gas, gas hydrates and carbonate concretions occurrence which are considered as high-risk factors for sub-sea developments. Analysis of P wave velocities obtained from the 3D seismic data and in-situ testing show that:

1- For low $P$ wave velocities identified from 3D seismic data and where the free gas existence was suspected, high excess pore pressure during the $C P T U$ rod penetration was measured. During the rod penetration, expansion of the gas bubbles and the low permeability of the gassy sediments were probably the causes of the high excess pore pressure.

2- Comparison between in-situ testing using the piezocone, recovered cores and $\mathrm{P}$ wave velocities derived from the first reflector of the 3D seismic data has shown that the 3D seismic data is a valuable tool to identify high-risk areas characterized by abnormal 
low or high P wave velocities. However, it was impossible to discriminate between the presence of gas hydrate and carbonate concretions from the $\mathrm{P}$ wave velocity anomalies alone.

3- CPTU testing has shown that distinction between gas hydrate and carbonate concretions can be done thanks to the excess pores pressure and the density measurements. Gas hydrate is characterized by a low density $(<1)$. However, while high excess pore pressure was generated during $C P T U$ testing in gas hydrate areas, a low excess pore pressure (in some cases lower than the hydrostatic pressure) was generated by CPTU testing in carbonate concretions areas. The reason is i) the low permeability of the hydrate phase, which impedes the dissipation of the pore pressure generated by the cone penetration and i) the high permeability of the carbonate concretions favouring pore pressure dissipation and the dilatancy of the sediment generated by the friction.

4- Sonic CPT measurements at site PV39-A and sub-bottom profile N1CH08 have revealed the co-existence between gas and gas hydrates. Due to the relative high water depth and low seafloor temperature, salinity is unlikely to be at the origin of the observed co-existence between free gas and gas hydrates. A tentative explanation of the co-existence between gas and gas hydrate in the study area is the high free gas migration within the pore of the gas hydrate where the absence of water prevents the formation of gas hydrate.

Acknowledgement: The support by officers and crew during NERIS1 and NERIS2 cruises is greatly appreciated, as is the dedication of the penetrometer staff during the NERIS2 cruise. The authors acknowledge Didier Drapeau for useful suggestions and remarks. Constructive comments by Martin Hovland and Anne M. Tréhu helped improve the manuscript significantly. 


\section{Reference List}

Arnaud J., Rappin D., Dunand J-P., Curinier V., 2004. High-Density picking for accurate velocity and anisotropy determination, $74^{\text {th }}$ Ann. Internat. Mtg: Soc. Of Expl. Geophysics, Session RC P2.3, 1627-1629.

Bohrmann, G., Greinert, J., Suess, E., Torres, M., 1998. Authigenic carbonates from the Cascadia subduction zone and their relation to gas hydrate stability. Geology 26, 647-650.

Brignoli, E.G.M., Gotti, M., Stokoe, K.H., 1996. Measurement of shear waves in laboratory specimens by means of piezoelectric transducers. Geotech. Test. J., 19(4), 384-397.

Brooks, J.M., Bryant, W.R., Bernard, B.B., Cameron N.R., 2000. The nature of gas hydrates on the Nigerian continental slope. Ann. N.Y. Acad. Sci., 912, 76-93.

Burke, K.C.B., 1972. Longshore drift, submarine canyons, and submarine fans. Am. Assoc. Petrol. Geol. Bull., 56, 1975-1983

Carcione, J.M., Tinivella, U., 2000. Bottom-simulating reflectors: seismic velocities and AVO effects. Geophysics, 65(1), 54-67.

Cauquil, E., Curinier, V., Legeron-Cherif, S., Piriac, F., Leron, A., Sultan, N., 2005. DeepWater Seabed Characterization Using Geostatistical Analysis of High Density/High Resolution Velocity Field, AAPG, Paris, abstr.

Chand, S., Minshull, T.A., Gei, D., Carcione, J.M., 2004. Elastic velocity models for gashydrate-bearing sediments a comparison. Geophys. J. Int., 159, 573-590

Cohen, H.A, McClay, K., 1996. Sedimentation and shale tectonics of the northwestern Niger Delta front. Mar. and Petrol. Geol., 13, 313-328.

Damuth J.E., 1994. Neogene gravity tectonics and depositional processes on the deep Niger Delta continental margin. Mar. and Petrol. Geol., 11, 320-346.

Damuth, J.E., Link, M.H., 1987. The seismic character of submarine fans and related deposits of the continental margin off the Niger Delta. Soc. Econ. Petrol. Mineral. Annu. Midyear Meeting Abstr. IV, 18.

Delteil, J.R., Valery, P., Montadert, L., Fondeur, C., Patrait, P., Mascle J., 1974. Continental margin in the northern part of the Gulf of Guinea. In: The Geology of Continental Margins (Eds C.A. Burk and C. L. Drake), Springer Verlag, New York, pp. 297-311.

Deptuck, M.E., Steffens, G.S., Barton, M.D., Pirmez, C., 2003. Architecture and evolution of upper fan channel belts on the Niger Delta slope and in the Arabian Sea. Mar. and Petrol. Geol., 20, 649-676.

De Gennaro, V., Delage, P., De Laure, E., 2004. Comportement des sols marins grande profondeur. Projet CLAROM no. CEP\&M 7510/02, final report, 41 pp. 
Ecker, C., Dvorkin, J., Nur, A., 1998. Sediments with gas hydrates: internal structure from seismic AVO. Geophysics, 63, 1659-1669.

Ecker, C., Dvorkin, J., Nur, A., 2000. Estimating the amount of gas hydrate and free gas from marine seismic data. Geophysics, 65(2), 565-573.

Emery, K.O., Uchupi, E., Phillips, J., Bowin, C., Mascle, J., 1975. Continental margin off western Africa: Angola to Sierra Leone. Am. Assoc. Petrol. Geol. Bull., 59, 2209-2265.

Evamy, B.D., Haremboure, J., Kamerling, P., Knapp, W., Molloy, F.A., Rowlands, P.H., 1978. Hydrocarbon habitat of Tertiary Niger Delta. Am. Assoc. Petrol. Geol. Bull., 62, 1-39

Galloway, W.E., 1986. Growth faults and fault-related structures of prograding terrigeneous clastic continental margins. Trans. Gulf Coast Assoc. Geol. Soc., 36, 121-128.

Gei, D., Carcione, J.M., 2003. Acoustic properties of sediments saturated with gas hydrate, free gas and water. Geoph. Prosp., 51, 141-157.

Graue, K., 2000. Mud volcanoes in deepwater Nigeria. Mar. and Petrol. Geol., 17, 959-974

Haskell N., Nissen S., Hughes M., Grindhaug J., Dhanani S., Heath R., Kantorowicz J., Antrim L., Cubanski M., Nataraj R., Schilly M., Wigger S., 1999. Delineation of geologic drilling hazards using 3-D seismic attributes. The leading edge, Tulsa, 373-382.

Heggland, R., 2003. Vertical Hydrocarbon Migration at the Nigerian Continental Slope: Applications of Seismic Mapping Techniques. Am. Assoc. Petrol. Geol. Annual Convention, Salt Lake City, May 11-14, abstr.

Helgerud, M.B., Dvorkin, J., Nur, A., Sakai, A., Collett, T.S., 1999. Elastic-wave velocity in marine sediments with gas hydrates: effective medium modelling. Geophys. Res. Lett., 26, 2021-2024.

Hospers, J., 1971. The geology of the Niger Delta area. In: The Geology of the East Atlantic Continental Margin (Ed. F. M. Delany), Great Britain Inst. Geol. Sci. Rep. No. 70/16, 121142

Hovland, M., Gallagher, J.W., 1997. Gas hydrate and free gas volumes in marine sediments: Example from the Niger Delta front. Mar. and Petrol. Geol., 14(3), 313-328.

Hovland, M., Judd, A.G., 1988. Seabed Pockmarks and Seepages. Impact on Geology, Biology and the Marine Environment. Graham \& Trotman Ltd., London, 293 pp.

Hovland, M., Svensen, H., Forsberg, C.F., Johansen, H., Fichler, C., Fossa, J.H., Jonsson, R., Rueslatten, H., 2005. Complex pockmarks with carbonate-ridges off mid-Norway: products of sediment degassing. Mar. Geol. 218 (1-4), 191-206.

Jakobsen, M., Hudson, J.A., Minshull, T.A., Singh, S.C., 2000. Elastic properties of hydratebearing sediments using effective-medium theory. J. geophys. Res. 105, 561-577. 
Knox, G.J., Omatsola, E.M., 1989. Development of the Cenozoic Niger Delta in terms of the 'Escalator Regression' model and impact on hydrocarbon distribution. In: Proceedings of the KNGMG Symposium Coastal Lowlands, Geology and Geotechnology, The Hague, 1987 (Eds W.J.M. van der Linden, S.A.P.L. Cloetingh, J.P.K. Kaasschieter, W.J.E. van der Graf, J. Vandenberglie and J.A.M. van der Gun), Kluwer Academic, Dordrecht, 181-202.

Le Chevalier, V., 2002. Application of seismic attribute for deep offshore seabed features characterization: preliminary results for the NERIS project, ENSPM report, $30 \mathrm{pp}$.

Lee, M.W., Hutchinson, D.R., Collett, T.S., Dillon, W.P., 1996. Seismic velocities for hydrate-bearing sediments using weighted equation, J. geophys. Res., 101, 20347-20358.

Liu, X., Flemings, P.B., 2006. Passing gas through the hydrate stability zone at southern Hydrate Ridge, offshore Oregon. Earth Planet. Sci. Lett., 241, 211 -226.

Marsset T., Marsset B., Vagner P., Sultan N., Voisset M., Cauquil E., 2005. Geohazard investigation on the Niger continental slope: New insights from near bottom geophysics. Ifremer/Total internal report 03/1.214.722, 39 pp.

Mascle, J., Bornhold, B.P., Renard, V., 1973. Diapiric structures off the Niger Delta. Am. Assoc. Petrol. Geol. Bull. 57, 2672-2678.

Meunier, J., Sultan, N., Jegou, P, Harmegnies, F. 2004. First tests of Penfeld: a new seabed penetrometer. Proceedings of the fourteenth international offshore and polar engineering conference, Toulon, France, 338-345.

Milkov, A.V. , Lee, Y.-J., Borowski, W.S., Torres, M.E., Xu, W., Tomaru, H., Trehu, A.M., Schultheiss, P., Dickens, G.R., Claypool, G.E., 2004. Co-existence of gas hydrate, free gas, and brine within the regional gas hydrate stability zone at Hydrate Ridge (Oregon margin): evidence from prolonged degassing of a pressurized core. Earth Planet. Sci. Lett., 222, 829843.

Nissen, S.E., Haskell N.L., Steiner, C. T., Coterill K.L., 1999. Debris flow outrunner blocks, glide tracks, and pressure ridges identified on the Nigerian continental slope using 3-D seismic coherency. The Leading edge, Tulsa, 595-599

Stoneley, R., 1966. The Niger Delta region in the light of the theory of continental drift. Geol. Mag., 103, 386-397

Suess, E., Carson, B., Ritger, S., Moore, J.C., Jones, M.L., Kulm, L.D., Cochrane, G.R., 1985. Biological communities at vent sites along the subduction zone of Oregon. The hydrothermal vents of the eastern Pacific: An overview. Biol. Soc. Washington Bull. 6, 474-484.

Sultan, N., 2007. Comment on "Excess pore pressure resulting from methane hydrate dissociation in marine sediments: A theoretical approach by Xu and Germanovich”. JGR, doi: 10.1029/2006JB004527.

Thomas, F., Rebours, B., Nauroy, J-F, Meunier, J., 2005. Mineralogical characteristics of the Gulf of Guinea deep water sediments. ISFOG, Perth, Australia, 1055-1061. 
Torres, M.E., Bohrmann, G., Brown, K., de Angelis, M., Hammond, D., Klinkhammer, G., McManus, J., Suess, E., Trehu, A., 1999. Geochemical observations on Hydrate Ridge, Cascadia margin, July 99. Reference 99-3, Oregon State University Data Report, 174, ref. 993.

Torres, M.E. , Wallmann, K., Tréhu, A.M., Bohrmann, G., Borowski, W.S., Tomaru, H., 2004. Gas hydrate growth, methane transport, and chloride enrichment at the southern summit of Hydrate Ridge, Cascadia margin off Oregon. Earth Planet. Sci. Lett., 226, 225-241.

Tréhu, A.M., Bohrmann, G., Rack, F., Torres, M.E., 2003. Leg 204 Scientific Party, Proc. ODP, Initial Reports, 204 [CD-ROM]. Ocean Drilling Program, Texas A\&M University, College Station TX 77845-9547, doi:10.2973/odp.proc.ir.204.2003.

Tréhu, A.M., Flemings, P., Bangs, N., Chevallier, J., Gracia, E., Johnson, J., Riedel, M., Liu, C.-S., Liu, X., Riedel, M., Torres, M.E., 2004. Feeding methane vents and gas hydrate deposits at south Hydrate Ridge. GRL, 31, L23310, doi:10.1029/2004GL021286.

Vanoudheusden, E., Sultan, N., Cochonat, P., 2004. Mechanical behaviour of unsaturated marine sediments: experimental and theoretical approaches. Mar. Geol., 213, 323-342.

Weber, K.J. and Daukoru, E.M., 1975. Petroleum geological aspects of the Niger Delta. Nigeria J. Miner. Geol., 12, 9-32

Westbrook, G., Carson, B., Musgrave, R., Shipboard Scientific Party, 1993. Init. Rep. ODP 146, $630 \mathrm{pp}$.

Wheeler, S.J., 1988. A conceptual model for soils containing gas bubbles. Géotechnique 38, 389-397.

Whiteman, A, 1982. Nigeria: its Petroleum Geology, Resources, and Potential, Vols1 and 2, Graham and Trotman, London, 394 pp. 


\begin{tabular}{|c|c|c|c|}
\hline Constituent & $\begin{array}{l}\text { Bulk Modulus, } K \\
\text { (GPa) }\end{array}$ & $\begin{array}{c}\text { Shear Modulus, } G \\
\text { (GPa) }\end{array}$ & $\begin{array}{c}\text { Mass-density, } \gamma \\
\left(\mathrm{g} / \mathrm{cm}^{3}\right)\end{array}$ \\
\hline Clay & 20.9 & 6.85 & 2.58 \\
\hline Calcite & 76.8 & 32 & 2.71 \\
\hline Quartz & 36.6 & 45 & 2.65 \\
\hline Gas hydrate & 7.9 & 3.3 & 0.90 \\
\hline Water & $2.4-2.6$ & 0 & 1.032 \\
\hline Methane Gas & $0.1-0.12$ & 0 & 0.23 \\
\hline
\end{tabular}

Table 1. Characteristics of CPTUs and Sonic CPTs locations.

\begin{tabular}{|c|c|c|c|}
\hline Location name & Test type & $\begin{array}{c}\text { Water Depth } \\
(\mathbf{m})\end{array}$ & $\begin{array}{c}\text { Maximum penetration } \\
(\mathbf{m})\end{array}$ \\
\hline PM16-A & CPTU & 1180 & 30.00 \\
\hline PM16-B & CPTU & 1192 & 29.82 \\
\hline PM22-A & CPTU & 1190 & 17.08 \\
\hline PM22-B & CPTU & 1232 & 14.58 \\
\hline PM22-C & CPTU & 1237 & 12.27 \\
\hline PM23-A & CPTU & 1226 & 17.57 \\
\hline PM23-B & CPTU & 1206 & 10.77 \\
\hline PM23-Bbis & CPTU & 1206 & 12.27 \\
\hline PM27-A & CPTU & 1182 & 4.90 \\
\hline PM29-A & CPTU & 1211 & 30.00 \\
\hline PM33-A & CPTU & 1196 & 28.68 \\
\hline PM33-B & CPTU & 1204 & 6.87 \\
\hline PM33-C & CPTU & 1202 & 9.62 \\
\hline PM33-D & CPTU & 1216 & 30.00 \\
\hline PM33-E & CPTU & 1173 & 30.00 \\
\hline PM33-F & CPTU & 1171 & 30.00 \\
\hline PM33-G & CPTU & 1164 & 18.34 \\
\hline PV39-A & Sonic CPT & 1180 & 15.00 \\
\hline PV39-B & Sonic CPT & 1210 & 17.04 \\
\hline PV40-A & Sonic CPT & 1200 & 4.64 \\
\hline PV40-B & Sonic CPT & 1210 & 15.00 \\
\hline
\end{tabular}

Table 2. Parameters set for the van Genuchten equation.

\begin{tabular}{|c|c|c|c|c|c|c|}
\hline Void ratio & Method & $\theta_{r}$ & $\theta_{s}$ & $\alpha$ & $m$ & $n$ \\
\hline 3.1 & Fitting & 13.22 & 100 & 12.962 & 0.1648 & 3.5432 \\
\hline 2 & Fitting & 13.22 & 100 & 4.8 & 0.1648 & 3.5432 \\
\hline 1.66 & Extrapolation & 13.22 & 100 & 4.5253 & 0.1648 & 3.5432 \\
\hline 1.1 & Extrapolation & 13.22 & 100 & 4.1 & 0.1648 & 3.5432 \\
\hline 1.03 & Extrapolation & 13.22 & 100 & 3.7 & 0.1648 & 3.5432 \\
\hline 1.0 & Extrapolation & 13.22 & 100 & 3.5 & 0.1648 & 3.5432 \\
\hline 0.95 & Extrapolation & 13.22 & 100 & 3.2 & 0.1648 & 3.5432 \\
\hline
\end{tabular}

Table 3. Elastic constants used wave velocity prediction (from Helgerud et al., 1999) 


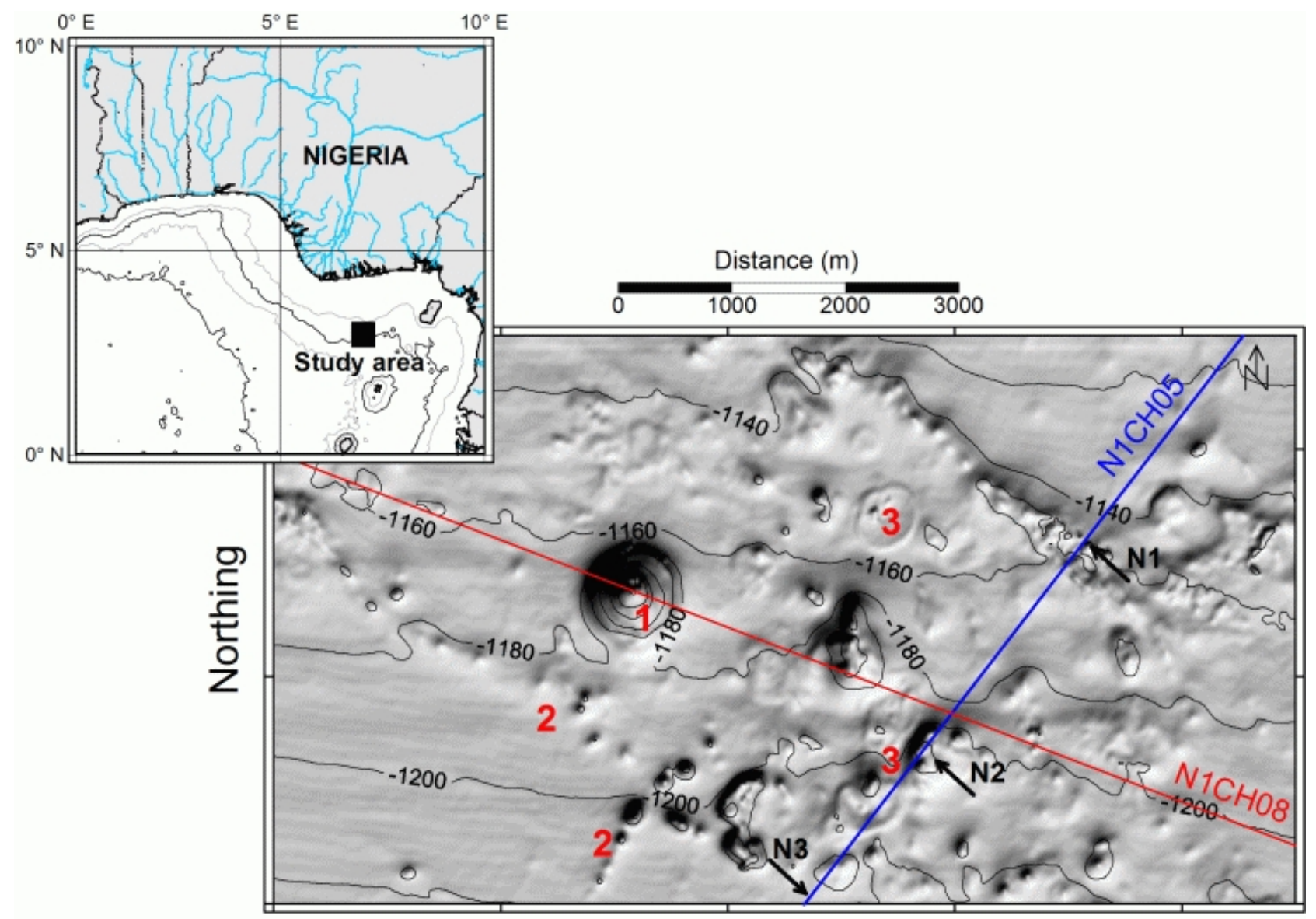

\section{Easting}

Figure 1. a) Location and b) shaded bathymetry of the study area showing 1: a large scale circular depression about $110 \mathrm{~m}$ deep and $700 \mathrm{~m}$ in diameter interpreted as a giant pockmark; 2: typical small scale circular depressions and 3) more atypical irregular structures on the seafloor. Seismic lines N1CH05 and N1CH08 are displayed in Figure2 and Figure19 respectively. 


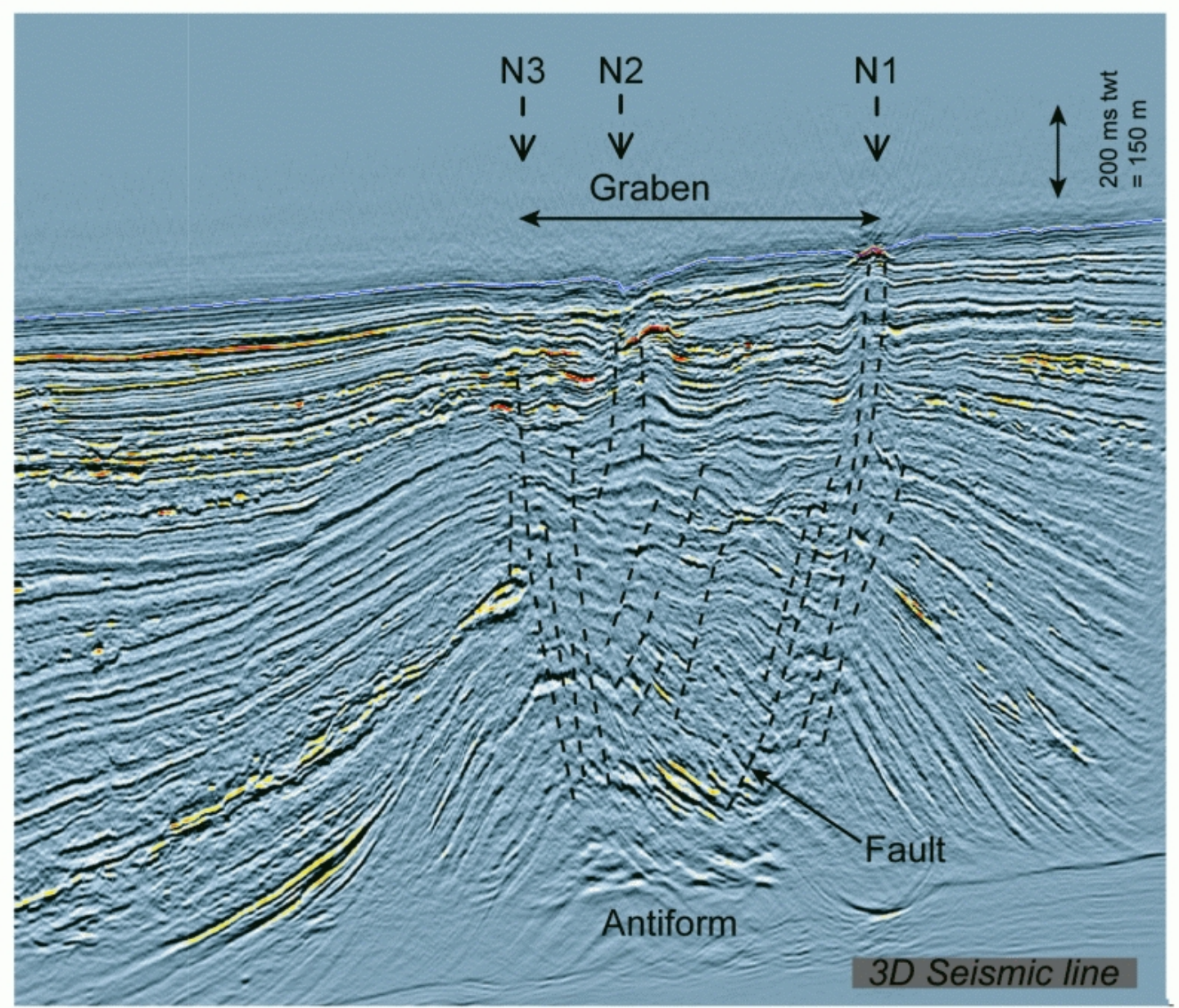

Figure 2. Seismic dip profile N1CH05 (3D HR line) showing the structural antiform and the major extrados faults that delineate a graben. N1 and N3 indicate two lineaments clearly expressed on the bathymetry map and N2 indicates a seafloor depression (pockmark). 
a)

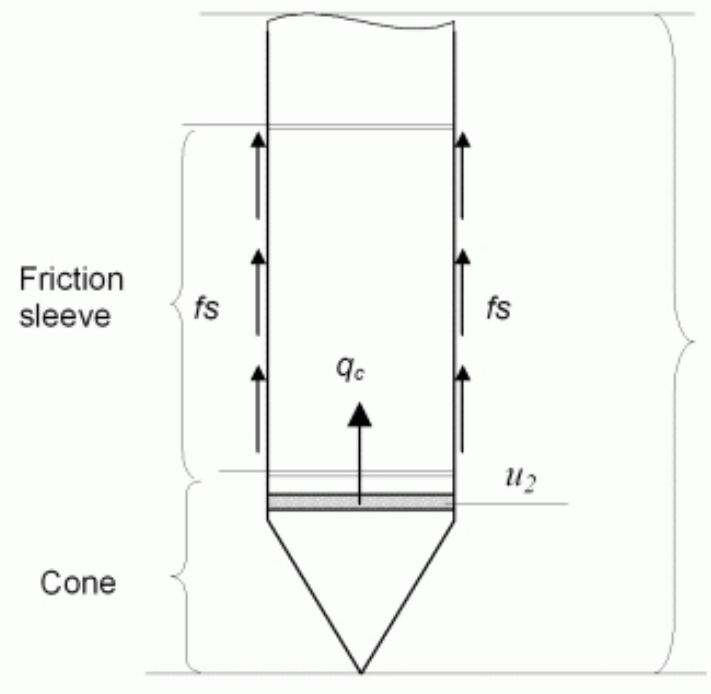

b)

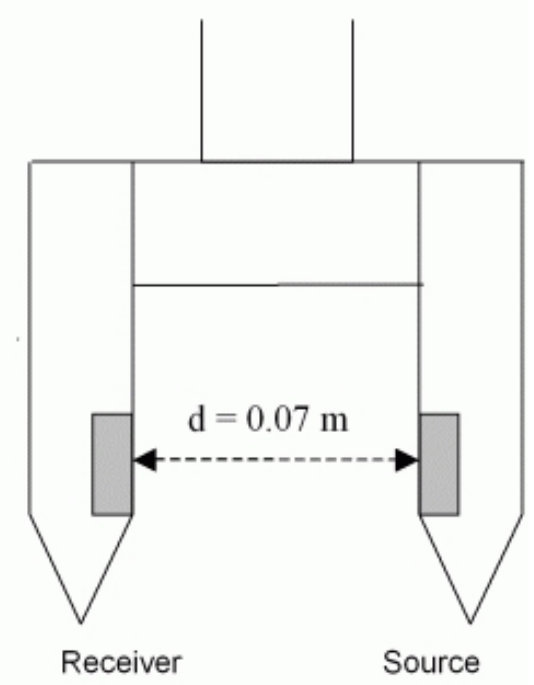

Figure 3. a) Scheme of the piezocone $C P T U$ and b) the Sonic $C P T$ 


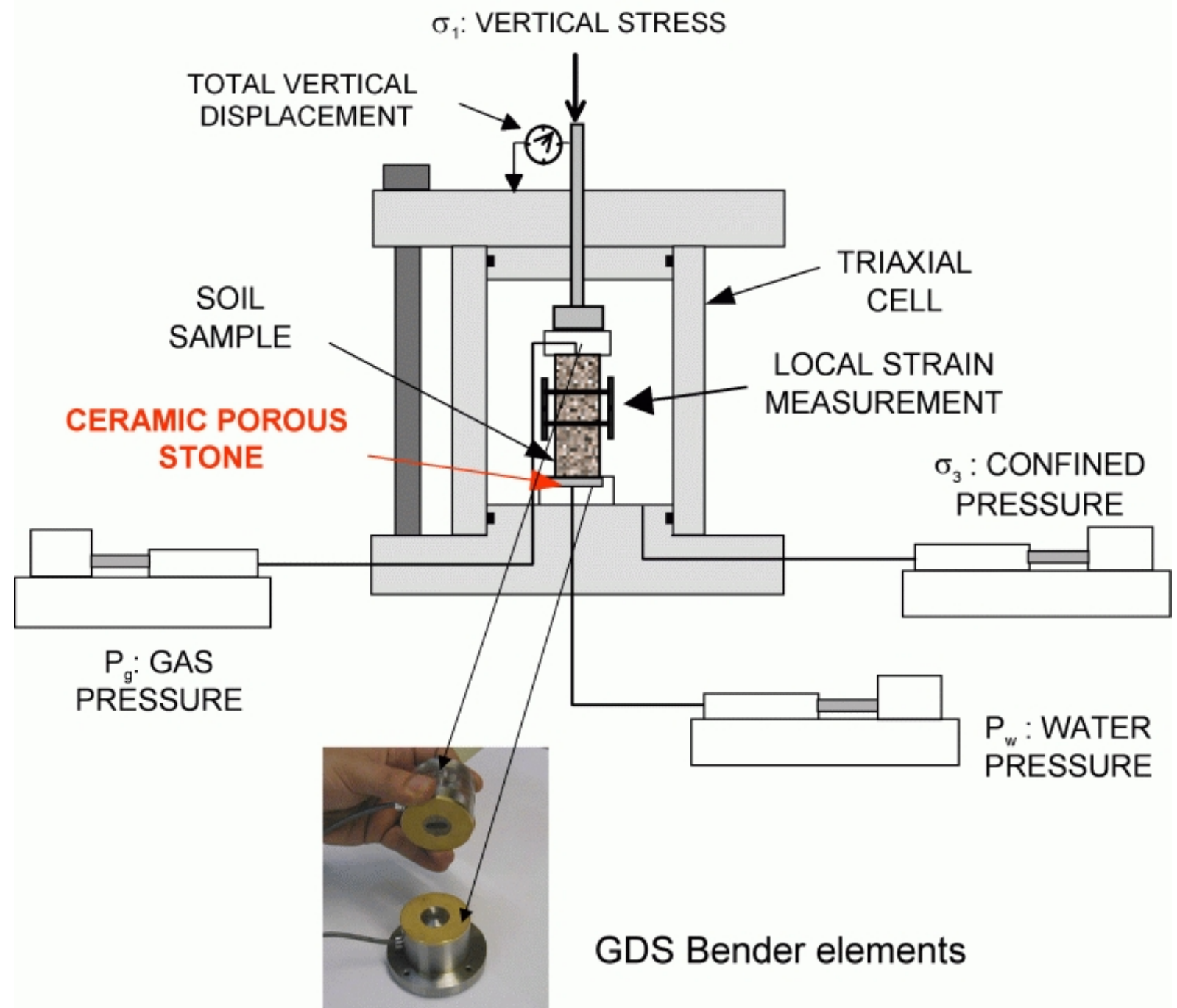

Figure 4. Special triaxial cell used to carry out tests on gassy soil. The bender elements are used during the tests in order to monitor the effect of the gas content on the shear wave and the compressional wave velocities. 
a)
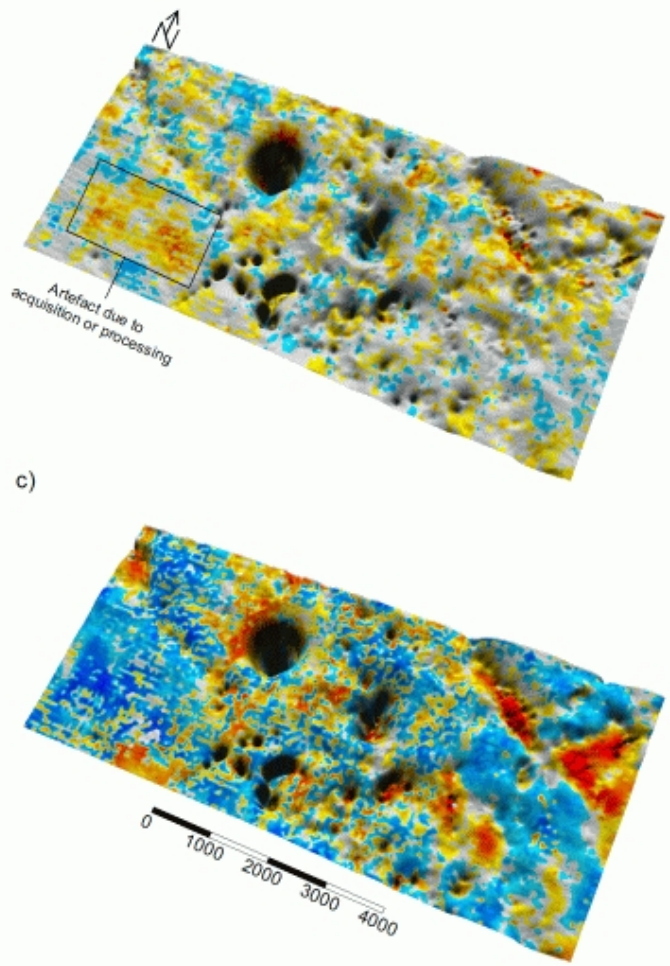

b)

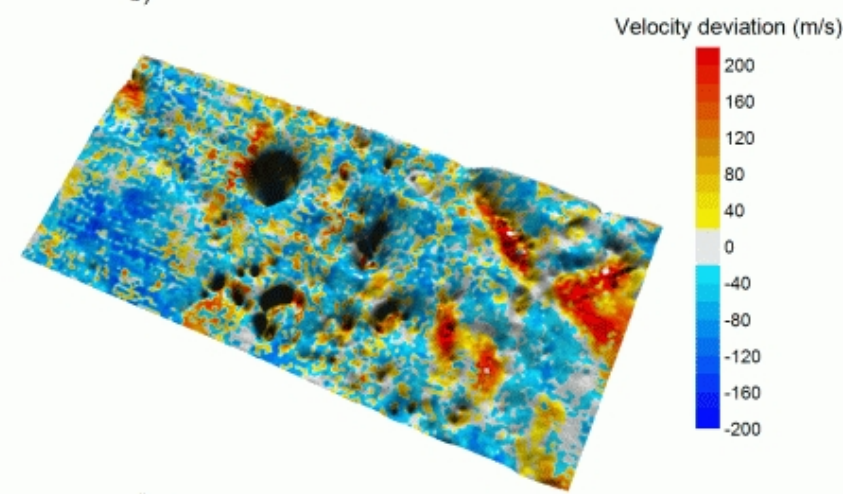

d)

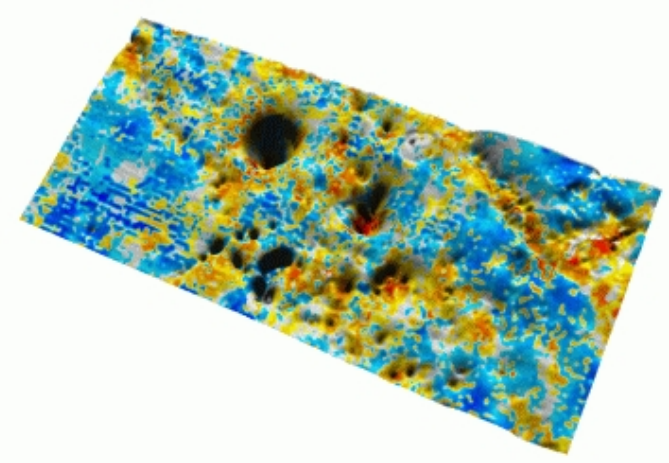

Figure 5. Projection on the seafloor of the velocity deviation from the reflector mean value for the first upper 4 reflectors. a) The first reflector represents the upper $15 \mathrm{~m}$ below the seafloor (mbsf) b) the second c) third and d) fourth reflectors characterize respectively the sediment at around $40 \mathrm{mbsf}, 60 \mathrm{mbsf}$ and $80 \mathrm{mbsf}$.

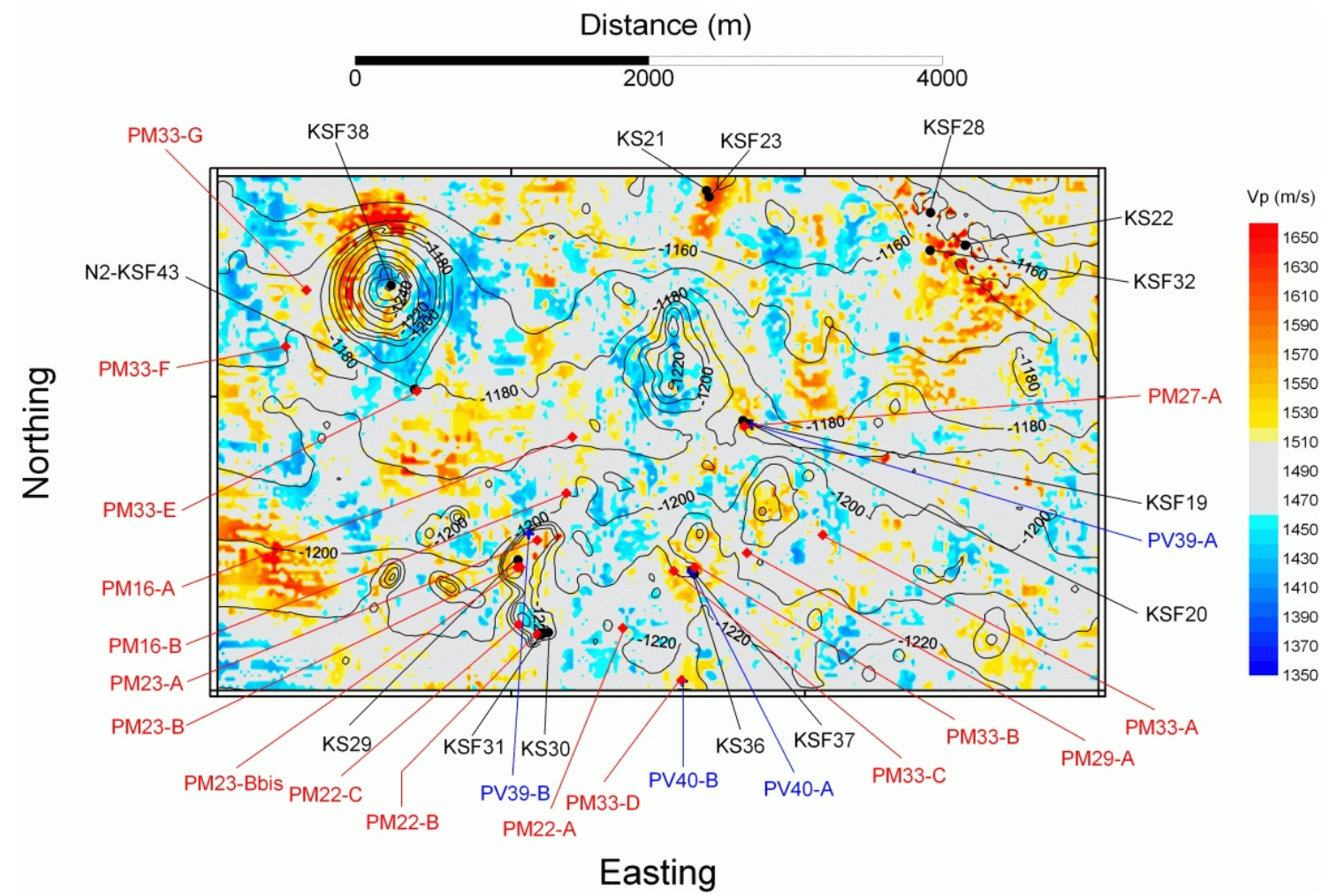

Figure 6. Bathymetry map showing: the gravity cores locations (KS) the CPTU (PM) and Sonic CPT (PV) measurements positions. 
a)

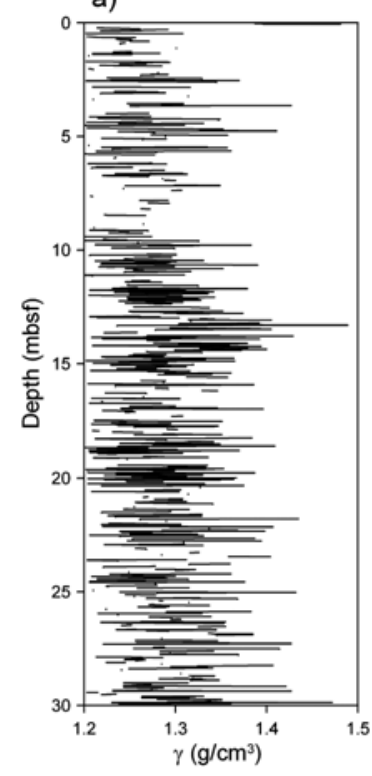

b)

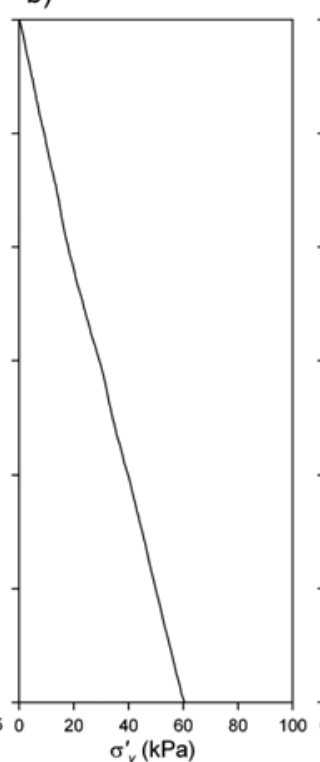

c)

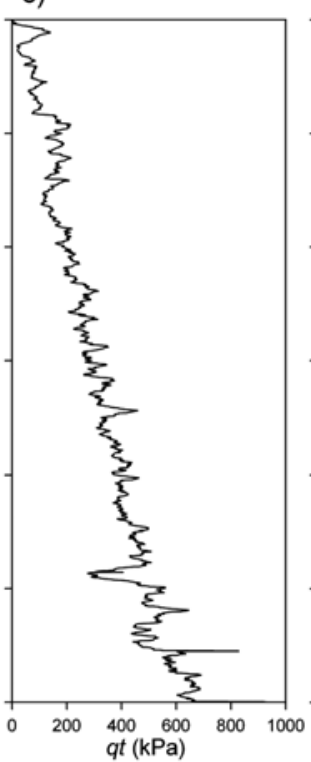

d)

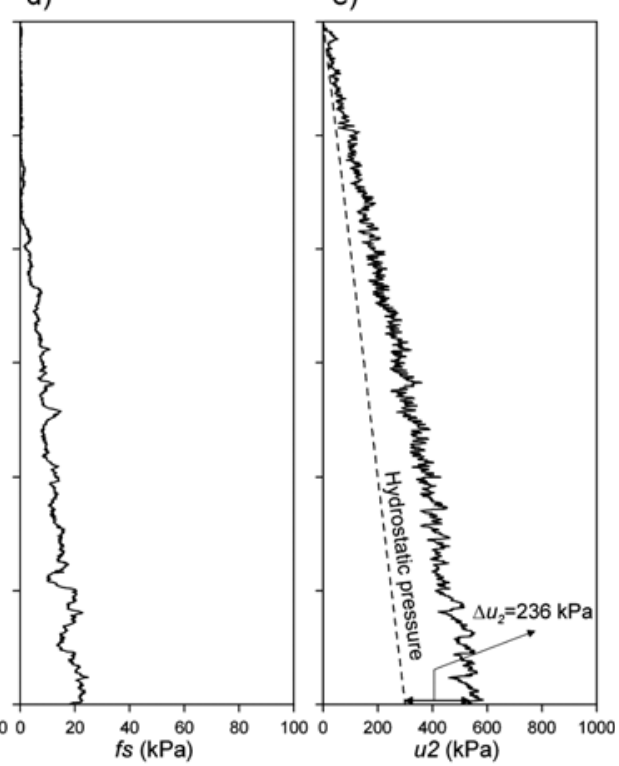

Figure 7. Site PM33-D: a) vertical effective stress, b) corrected cone resistance, c) friction and d) pore pressure as a function of depth.

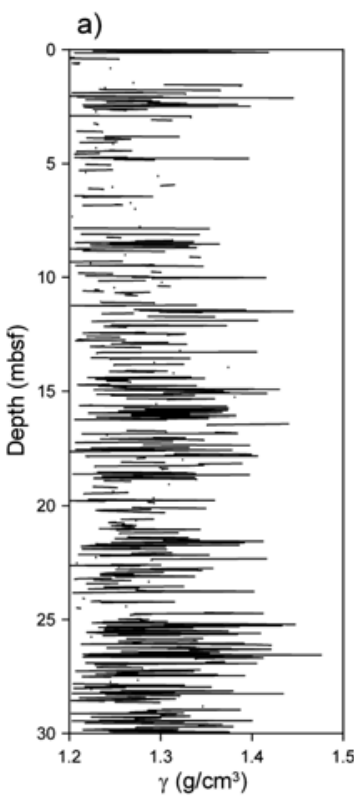

b)

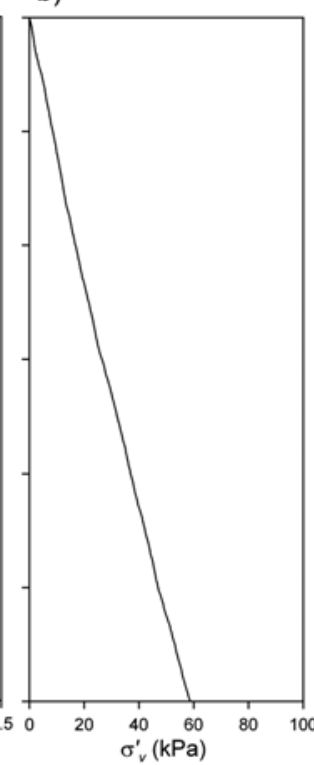

c)

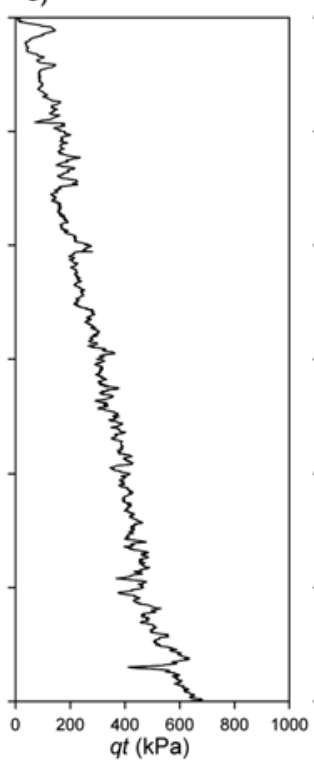

d)

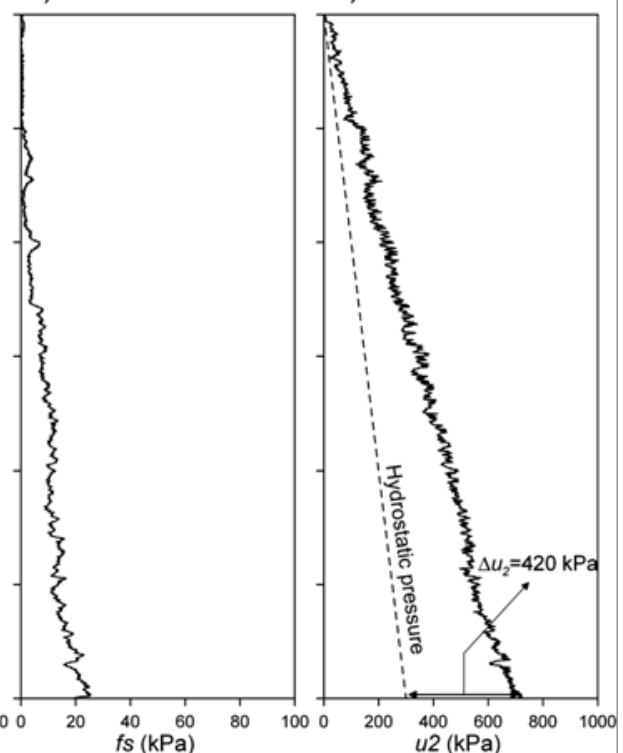

Figure 8. Site PM33-E : a) vertical effective stress, b) corrected cone resistance, c) friction and d) pore pressure as a function of depth. 


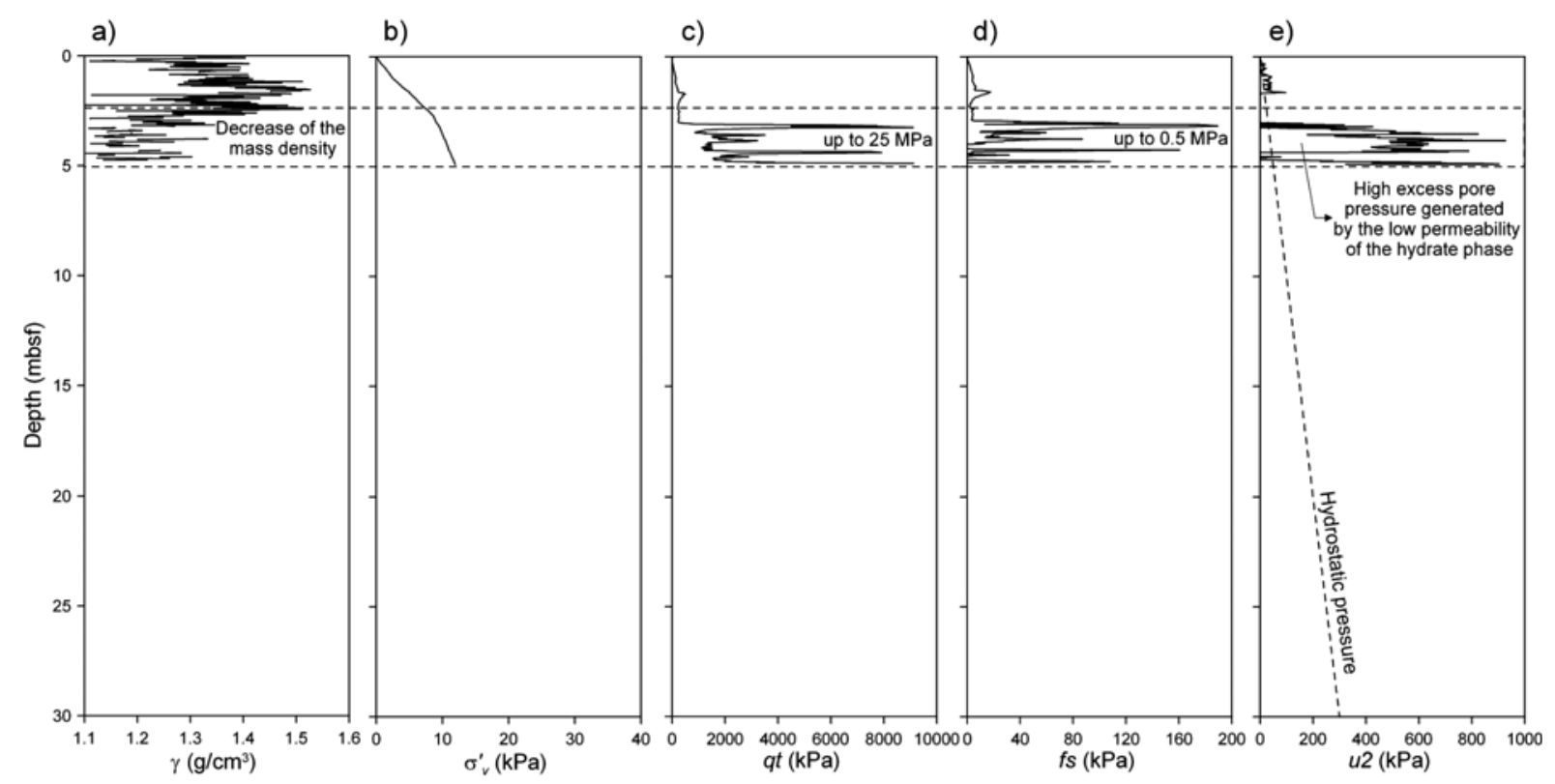

Figure 9. Site PM27-A: a) vertical effective stress, b) corrected cone resistance, c) friction and d) pore pressure as a function of depth.

a)

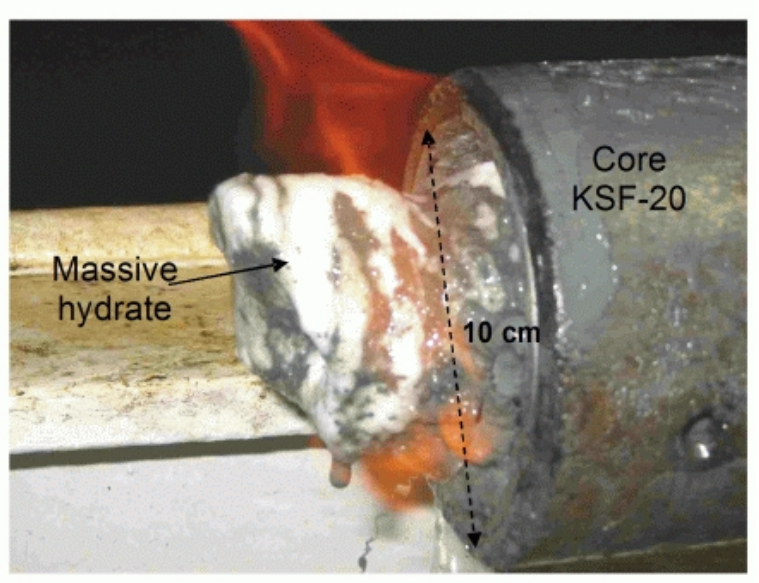

b)

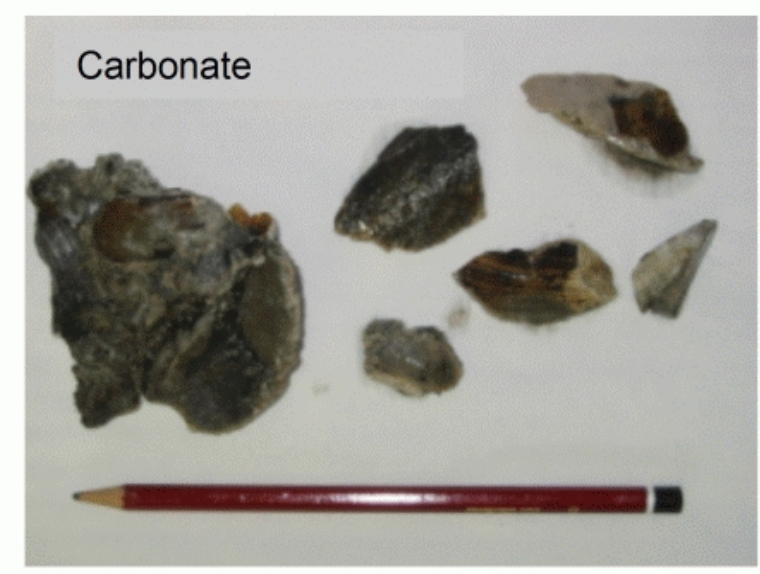

Figure 10. a) Massive gas hydrate recovered from core KSF20; similar gas hydrate samples were recovered from cores KSF19, KS21, KSF23, KS36 and KSF37 (for position see Figure6). b) Carbonate concretions recovered during NERIS1 survey. 


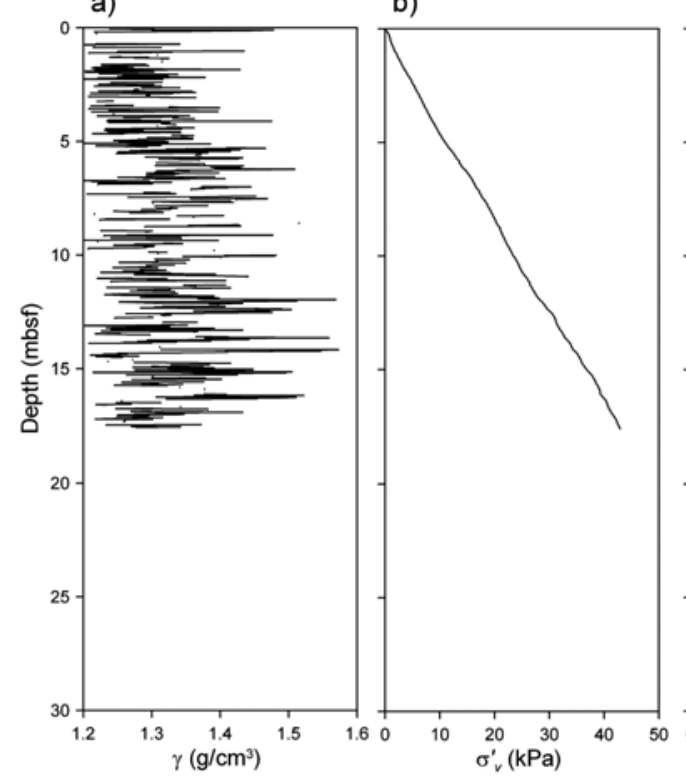

c)

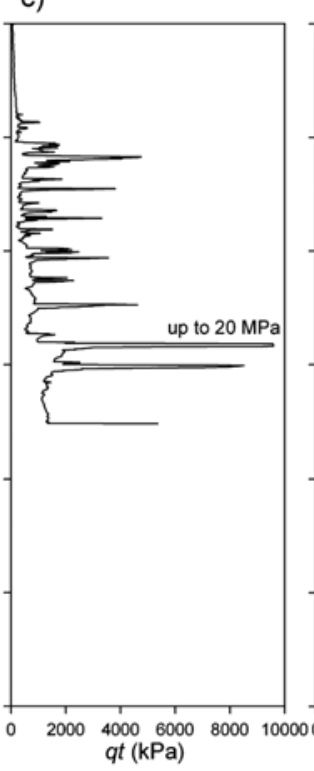

d)

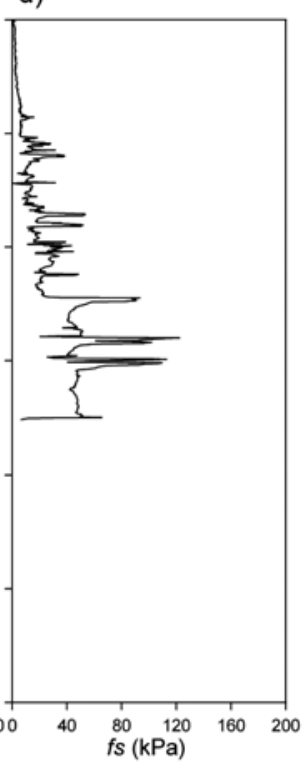

e)

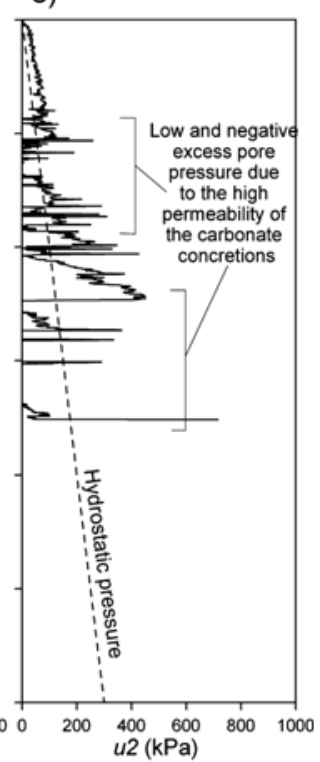

Figure 11. Site PM23-A: a) vertical effective stress, b) corrected cone resistance, c) friction and d) pore pressure as a function of depth.
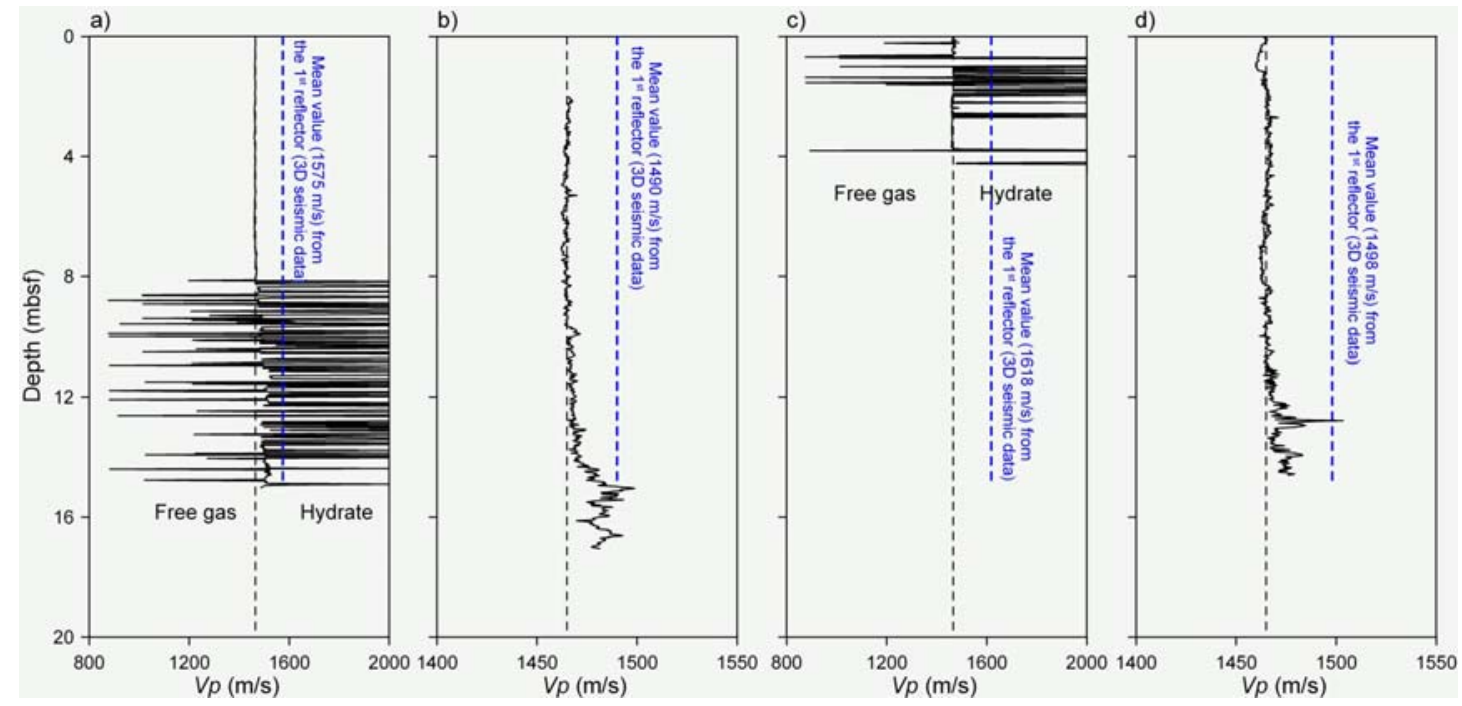

Figure 12. Compressional wave velocity as a function of depth obtained from in situ Sonic CPT measurements compared to $V_{p}$ values obtained from the $1^{\text {st }}$ reflector (for the upper $15 \mathrm{~m}$ ) of the 3D seismic data at site: a) PV39-A b) PV39-B c) PV40-A d) PV40-B. 


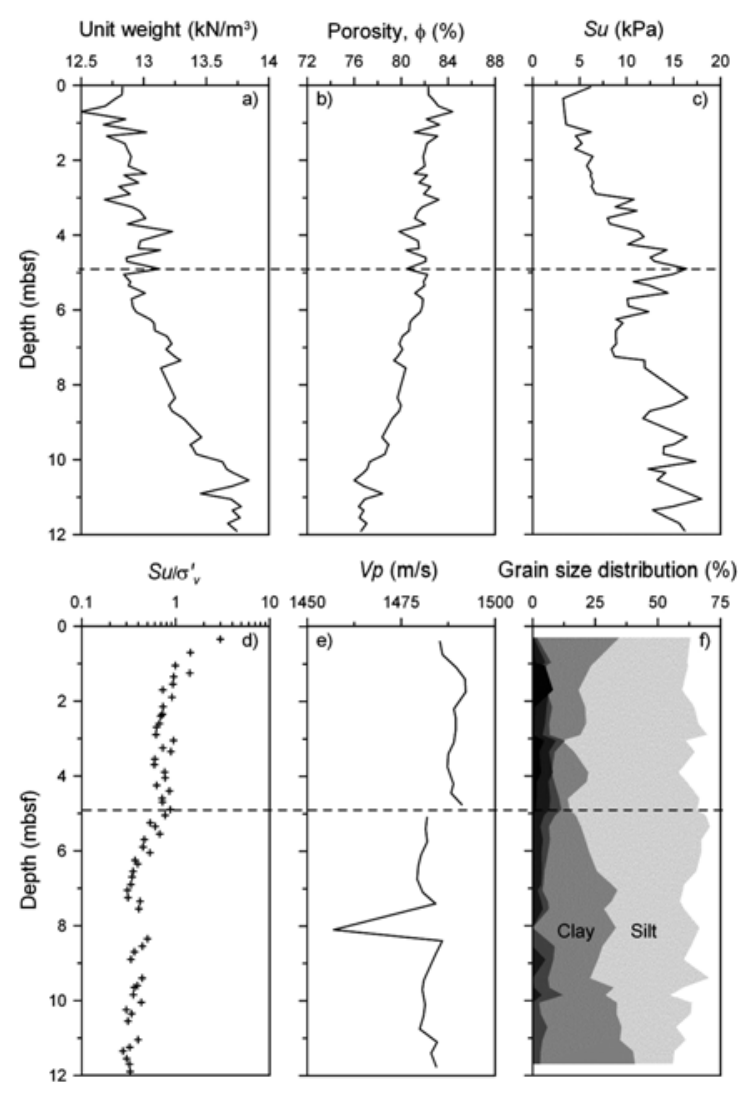

Figure 13. Results from geotechnical tests carried out on samples from core N2-KSF43 : a) Unit weight, b) porosity, c) undrained shear strength, d) ratio between undrained shear strength and vertical effective stress, e) $\mathrm{P}$ wave velocity measured in labaoratory and f) grain size distribution as a function of depth.

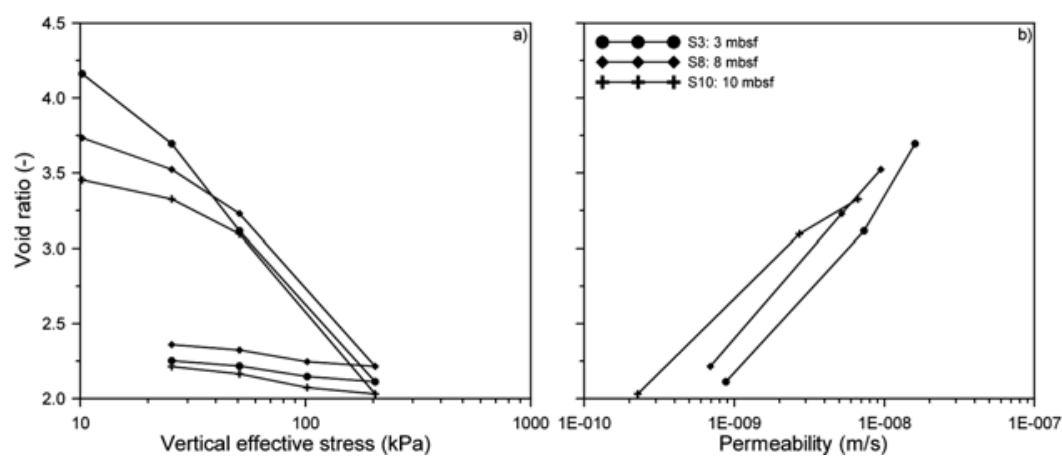

Figure 14. Results from a) oedometer tests and b) permeability tests showing the change of the permeability coefficients with the void ratio (core N2-KSF43). 

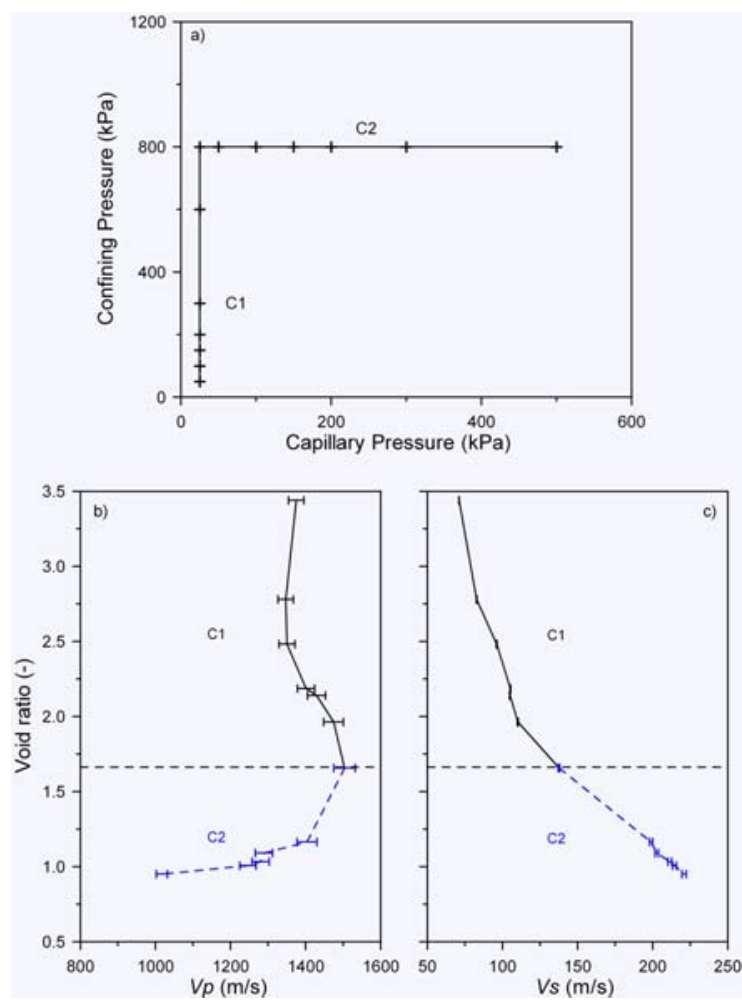

Figure 15. a) Stress paths carried out in the special triaxial cell in order to characterize the acoustic properties of the sediment from the study area. b) compressional wave velocities and b) shear wave velocities for stress paths C1 and C2.
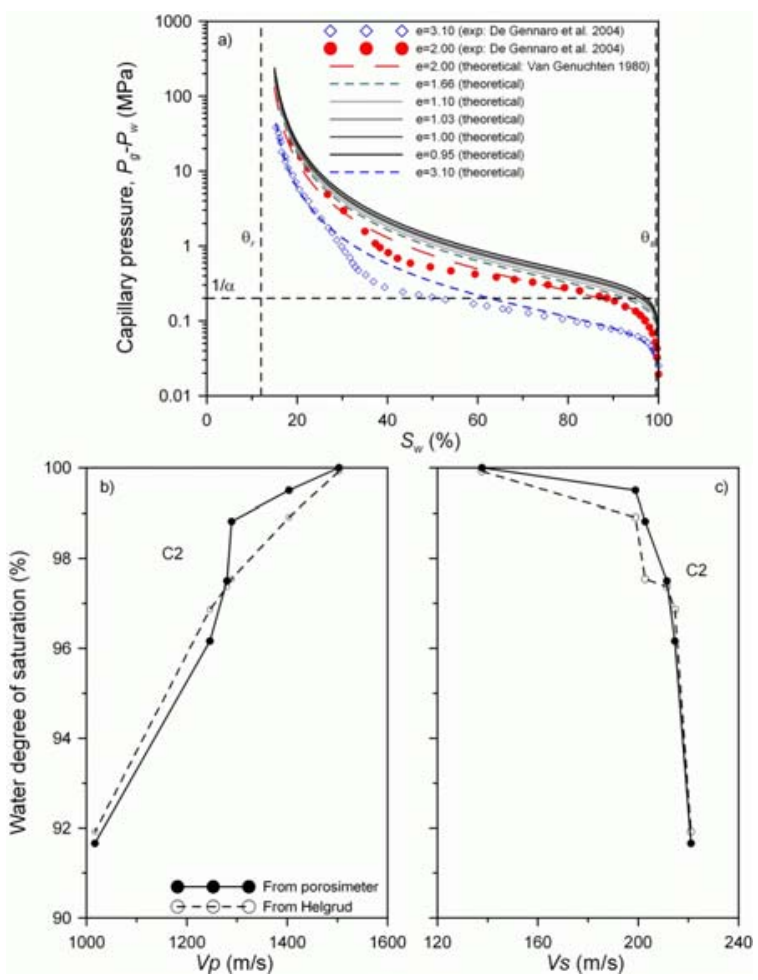

Figure 16: a) Diagram showing the parameters used in the Van Genuchten equation and the effect of the initial void ratio on the retention curve (capillary pressure-water degree of saturation). b) Comparison between $\mathrm{P}$ wave and c) shear wave experimental results and the Helgerud et al. model (1999). 

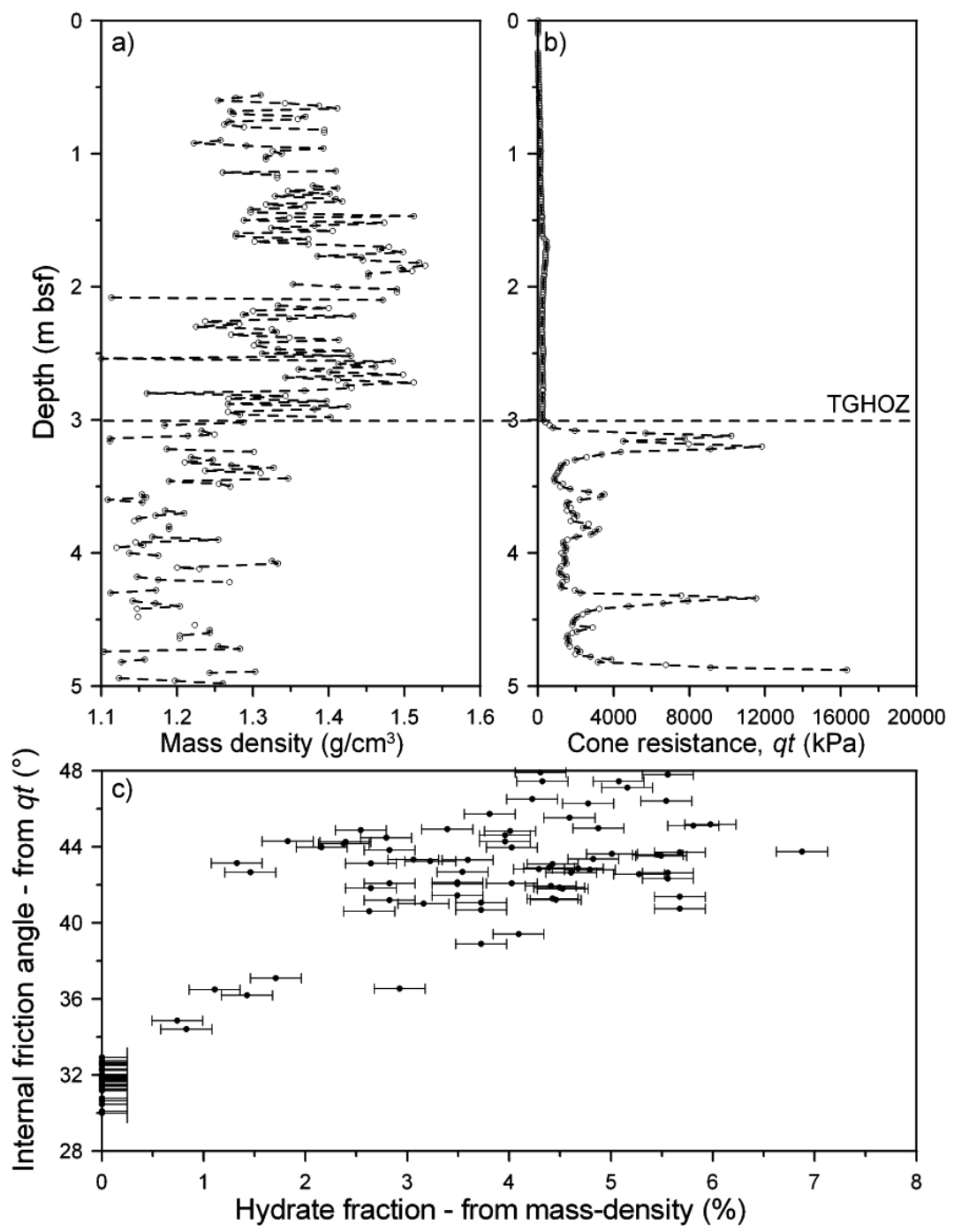

Figure 17. In-situ CPTU measurements showing the variation as a function of depth of a) the sediment massdensity and b) the cone resistance qt. c) Hydrate fraction $\eta$ (calculated from the mass-density of the sediment) as a function of the internal friction angle $\varphi$ (calculated from the cone resistance qt) (from Sultan, 2007). 


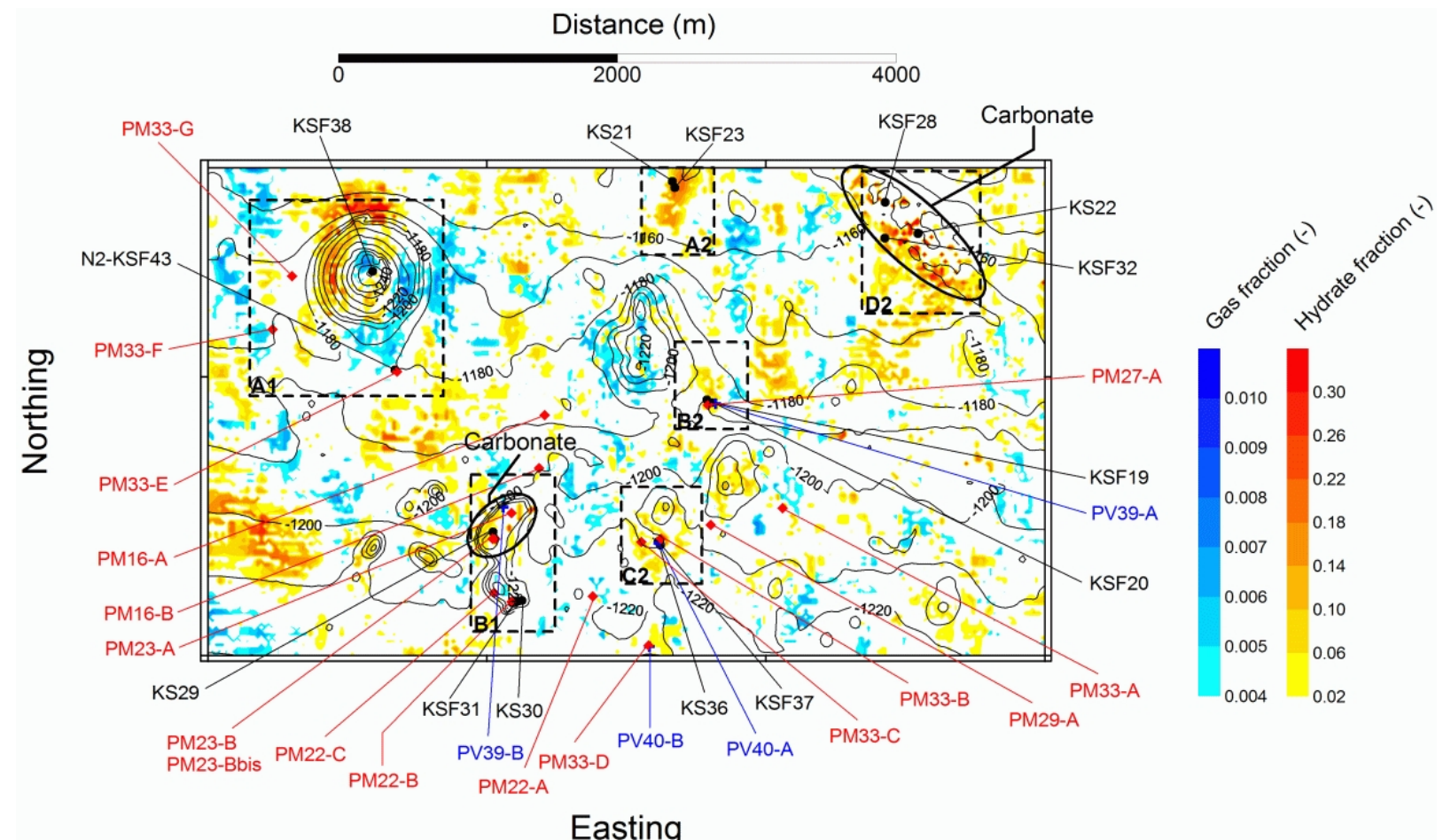

Figure 18. Gas and gas hydrate distribution contours obtained from the first reflector (around $15 \mathrm{mbsf}$ ) of the 3D seismic cube and CPTS and Sonic CPTS locations - gas hydrate is considered as a component of the matrix.

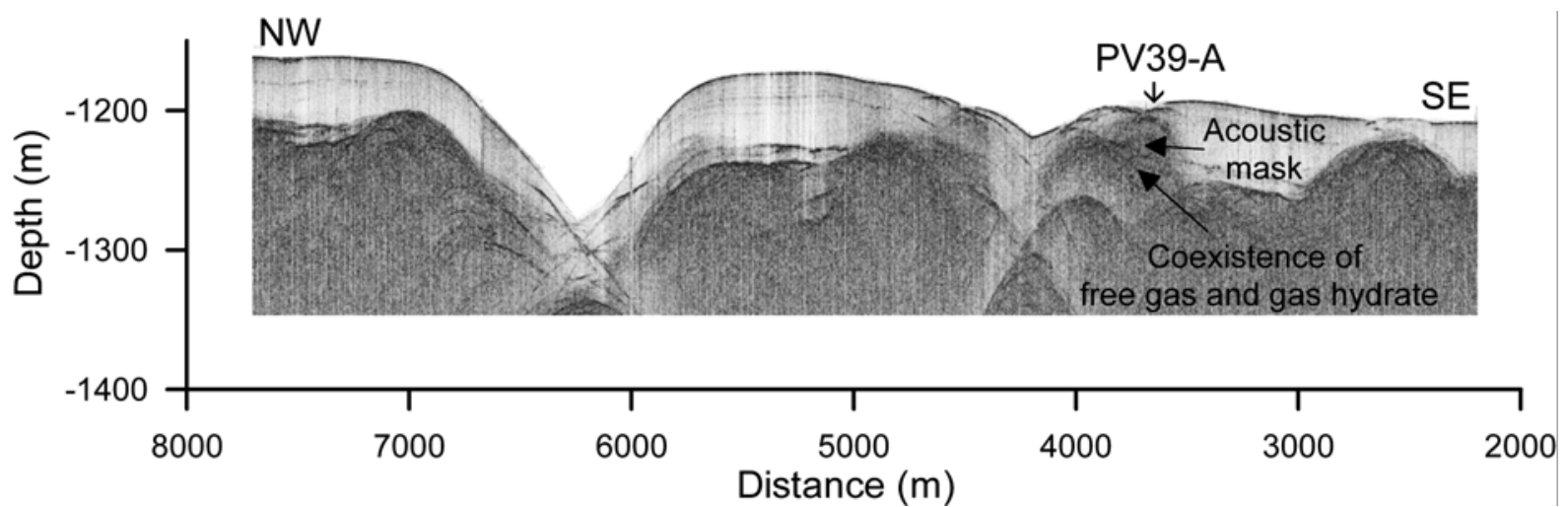

Figure 19. Chaotic facies from N1CH08 profile indicating the co-existence between free gas and gas hydrates (for location see Figure 1). 